\title{
Aspectos Moleculares Da GÊnese e Progressão De Lesões PERIAPICAIS IndUZIDAS EXPERIMENTALMENTE EM Camundongos
}

\author{
Tese apresentada à Faculdade de Odontologia de Ribeirão \\ Preto da Universidade de São Paulo, para obtenção do título \\ de Doutor em Ciências. \\ Programa: Odontopediatria \\ Área de Concentração:Odontopediatria \\ Orientador: Profa. Dra. Raquel Assed Bezerra Segato \\ Co-orientador:Prof. Dra. Erika Calvano Küchler
}

Ribeirão Preto

2017 
AUTORIZO A REPRODUÇÃO E/OU DIVULGAÇÃO TOTAL OU PARCIAL DA PRESENTE OBRA, POR QUALQUER MEIO CONVENCIONAL OU ELETRÔNICO, DESDE QUE CITADA A FONTE.

Driely Barreiros

Ficha Catalográfica

Barreiros, Driely

Aspectos moleculares da gênese e progressão de lesões periapicais induzidas experimentalmente em camundongos. Ribeirão Preto, 2017.

106p. : il. ; $30 \mathrm{~cm}$

Tese de Doutorado apresentada à Faculdade de Odontologia de Ribeirão Preto/USP - Área de Concentração: Odontopediatria.

Orientador: Profa. Dra. Raquel Assed Bezerra Segato

1.Camundongos; 2.Camundongos knockout, 3.TLR2; 4.MyD88; 5.MMP2; 6.MMP9; 7. Lesão periapical; 8.Sistema RANK, RANKL e OPG

Versão corrigida da Dissertação/Tese. A versão original se encontra disponível na Unidade que aloja o Programa 
DRIELY BARREIROS

\section{ASPECTOS MOLECULARES DA GÊNESE E PROGRESSÃO DE LESÕES PERIAPICAIS INDUZIDAS EXPERIMENTALMENTE EM CAMUNDONGOS}

Tese apresentada à Faculdade de Odontologia de Ribeirão Preto da Universidade de São Paulo, para obtenção do título de Doutor em Ciências.

Programa: Odontopediatria

Área de Concentração: Odontopediatria

Orientador: Profa. Dra. Raquel Assed Bezerra Segato

Co-orientador: Prof. Dra. Erika Calvano Küchler

Data da defesa:

\section{Banca Examinadora}

Prof. Dr.

Julgamento:

Assinatura:

Prof. Dr.

Julgamento:

Assinatura:

Prof. Dr.

Julgamento:

Assinatura:

Prof. Dr.

Julgamento:

Assinatura:

Prof. Dr.

Julgamento:

Assinatura: 



\section{DADOS CURRICULARES}

\section{DRIELY BARREIROS}

Nascimento

Filiação

2007-2010

2008-2009

2011-2012

2011-2013
17 de novembro de 1986 - São Carlos/SP

Valmir Barreiros

Silvana de Cássia Garcia Ferreira Barreiros

Curso de Graduação

Faculdade de Odontologia - FHO

Iniciação Científica - Bolsista CNPq

Universidade Federal de Pernambuco

Aperfeiçoamento em Atendimento Odontológico a Pacientes Especiais.

Faculdade de Odontologia de Ribeirão Preto - FORP/USP

Curso de Especialização em Odontopediatria

Associação dos Cirurgiões Dentistas de Araraquara Araraquara/SP

Curso de Pós-Graduação (Mestrado) em Odontologia Área de Concentração: Odontopediatria. Bolsista CAPES Faculdade de Odontologia de Ribeirão Preto/USP

Curso de Pós-Graduação (Doutorado) em Odontologia Área de Concentração: Odontopediatria. Bolsista CAPES Faculdade de Odontologia de Ribeirão Preto/USP 



\section{"Desistir?}

Eu já pensei seriamente nisso, Mas nunca me levei realmente a serio, É que tem mais chão nos meus olhos Do que cansaço nas minhas pernas, Mais esperança nos meus passos, Do que tristeza nos meus ombros, Mais estrada no meu coração Do que medo na minha cabeça." 

OFEREÇOESSETRABALHO

Ofereço este trabalho a Deus,por todas as bênçãos e coisas maravilhosas que Ele tem feito em minha vida. Senhor, muito obrigada pelodom vida. 



\section{DEDICATÓRIA}

Dedico esse trabalho ao João Pedro, filho amado, que tanto esperei. Você chegou no melhor momento de nossas vidas e está concluindo junto comigo este trabalho que foi tão desafiador quanto será criá-lo nos preceitos de Deus, nosso Senhor. Hoje posso dizer que você é o motivo de inspiração da minha vida, faz com que meus dias sejam melhores e que eu queira ser uma pessoa melhor a cada dia.

Ao meu marido Moisés Alcebíades de Oliveira que nunca deixou de acreditar nos meus sonhos e fez de tudo para que eles pudessem ser realizados. Um desses sonhos é a conclusão deste doutorado, pois ele confiou em mim e me ajudou a seguir firme em minhas decisões. Eu te amo tanto que palavras são pouco pra expressar esse sentimento. E o amo mais ainda depois do presente maravilhoso que estamos esperando, o nosso filho amado João Pedro.

Aos meus pais Valmir Barreiros e Silvana de Cássia Garcia Ferreira Barreiros, que apesar de não possuírem estudo nenhum, Lutaram, Gatalharam e me incentivaram para que eu pudesse ter a formação que tenho hoje. Ser dentista era um sonho de criança que só foi possível graças a vocês que sempre acreditaram em meu potencial. Obrigada por todo carinho e esforço. Amo vocês incondicionalmente! São os methores pais que eu poderia ter tido e com certeza serão os melhores avós do mundo.

Ao meu irmão Victor Baarreiros por todo companheirismo, carinho e atenção! Amo você desde sempre e para sempre!

Essa conquista também é de vocês

Obrigada por tudo! 



\section{AGRADECIMENTOS ESPECIAIS}

\section{Aos queridos Mestres}

À Profa Dra. Raquel Assed Bezerra Segato, minha orientadora. Muito obrigada por ter me aceito como afuna, num momento em que nem eu acreditava mais em mim na carreira da pós-graduação. A sua paciência, seus gestos de carinho e a sua disponibilidade foram fundamentais para a conclusão dessa tese de doutorado. Não tenho palavras para agradecer a sua generosidade em me acolher! Que Deus abençoe você sempre e toda a sua família! Muito obrigada mesmo professora!

À Profa Dra Eriķa Calvano Küchler,minha co-orientadora, que me fez enxergar a pós-graduação como algo leve, com suas dicas maravilhosas. Fez-me entender que o potencial estava em mim e não nas outras pessoas. Tornouse minha amiga e me ajudou em todos os momentos que mais precisei. Minha eterna gratidão a você, pois tudo se tornou mais leve durante esses 4 anos! Que a amizade continue por muitos anos! Grande beijo!

Ao Prof Dr. Paulo Nelson Filho e ao Dr. Francisco Wanderley Garcia Paula e Silva por toda a disponibilidade e paciência em transmitir seus conhecimentos. Exemplos de mestres! Muito obrigada!

À Profa Dra Maria Cristina Borsatto, que desde o mestrado, esteve sempre presente em minha vida. Sua alegria contagiante nos motiva todos os dias a querer o melhor para as nossas vidas! Muito obrigada por ser um exemplo de professora, que quero carregar para a minha vida toda!

\section{Às queridas amigas em Ribeirão Preto}

Katharina Morant Holanda de Oliveira, Daniela Silva Barroso de Oliveira,Carolina Maschietto Puccinelli, Larissa Nogueira Soares Ribeiro, Priscilla Romualdo Coutinho, Ana Carolina Fumes.Cada uma com seu jeito conquitaram a minha amizade. Obrigadapelo companheirismo, 6om-humor, apoio e incentivo mútuos, momentos de descontração e estresse compartilhado durante o Doutorado! Espero que a distância não apague o brilho de nossa amizade. Muito obrigada por tudo! 



\section{AGRADECIMENTOS}

À Universidade de São Paulo, na pessoa do atual reitor, Prof. Dr. Marco Antonio Zago,e do vice-reitor, Prof. Dr. Vahan Agopyan.

À Faculdade de Odontologia de Ribeirão Preto da Universidade de São Paulo, na pessoa da atual diretora, Profa. Dra. Léa Assed Bezerra da Silva, e do vice-diretor, Prof. Dr. Arthur Belém Novaes Júnior.

À Coordenação do Curso de Pós-Graduação em Odontopediatria da Faculdade de Odontologia de Ribeirão Preto da Universidade de São Paulo, na pessoa da coordenadora, Profa. Dra. Raquel Assed Bezerra Segatoe da vicecoordenadoraProfa. Dra. Lea Assed Bezerra da Silva.

ÀCAPES (Coordenação de Aperfeiçoamento de Pessoal de Nível Superior), pela bolsa concedida.

Aos professores da disciplina de Odontopediatria da Faculdade de Odontologia de Ribeirão Preto da Universidade de São Paulo: Profa. Dra. Sada Assed,Profa. Dra. Aldevina Campos de Freitas,Profa. Dra. Alexandra Mussolino de Queiroz,Profa. Dra. Andiara de Rossi Daldegan,Prof Fabricio Kitazono de CarvalhoProfa. Dra. Kranya Victoria Díaz Serrano, Prof. Dr. Alberto Consolaroexemplos de dedicação à profissão, pelos ensinamentos, apoio e contribuições científicas, pela convivência sempre agradável! Muito obrigada a todos.

Aos professores da disciplina de Ortodontia da Faculdade de Odontologia de Ribeirão Preto da Universidade de São Paulo: Prof. Dr. Fábio Lourenço Romano, Prof. Dr. José Tarcísio Lima Ferreira, Profa. Dra. Mírian Aiko Nakane Matsumoto, Profa. Dra. Maria Bernadete Sasso Stuani, pela convivência agradável no mesmo departamento, pelas orientações e ensinamentos transmitidos.

Aos Funcionários da Faculdade de Odontologia de Ribeirão Preto:

Marília Pacífico Lucisano, pela disponibilidade e atenção sempre dispensadas a mim quando eu precisava!

Nilza Letícia Magalhães, pelo 6om-humor, carinho, paciência e toda a ajuda técnica na realização deste trabalho! Por sempre estar disposta a ajudar, por suas risadas que animavam o meu dia, pela amizade. Muito obrigada Nilza Maria!

Carolina Paes Torres Mantovani, pela convivência agradável, tantos ensinamentos transmitidos,pelas palavras de apoio e encorajadoras, desde o mestrado. Sempre pronta a ajudar! Uma pessoas incrível com uma luz que irradia quando passa. Muito Obrigada por tudo!

Marco Antônio dos Santos e Fátima Aparecida Jacinto Daniel por todoapoio, disponibilidade, 6omhumordurante as atividades laboratoriais.

Micheli Cristina Leite Rovanholo, Matheus Morelli Zanela e Filomena Leli Placciti, pela prontidão em ajudar, auxiliar, orientar e aconselhar quando era preciso.

Aos funcionários da Clínica 1: José Aparecido Neves do Nascimento, Vera do Nascimento Scandelai e Karina Dadalt Quaglio, pela convivência agradável e pelo apoio nas atividades de clínica junto à graduação. 
Aos funcionários do Biotério da Faculdade de Odontologia de Ribeirão Preto da Universidade de São Paulo, Antônio Sérgio Aparecido Mesca, Aline Aparecida Ferraresi Tiballi, Antônio Massaro e Raphael Martini Vicente, pela paciência, disposição em ajudar e cuidado com os animais.

Aos colegas da Pós-Graduação em Odontopediatria da Faculdade de Odontologia de Ribeirão Preto da Universidade de São Paulo, não citarei nomes com medo de esquecer alguém, mais saibam que cada um fez parte desses anos em que passei na FORP, obrigada pelo incrivel "intercâmbio cultural", pela troca de experiências e pela convivência sempre agradável.

Aos amigos de São Carlos, que por muito tempo, tivemos que lidar com a distância e falta de tempo em nos encontrar, vocês também tem parte nessa conquista. Obrigada por entenderem as minhas ausências e mesmo assim não deixar que o tempo abalasse a nossa amizade.

A todaa minha família que sempre estiveram ao meu lado, me apoiando, acreditando que meus sonhos seriam possíveis. Obrigada por entender a minha ausência e mesmo assim vibrar comigo as minhas vitórias. Amo vocês! 
Barreiros, D.Aspectos moleculares da gênese e progressão de lesões periapicais induzidas experimentalmente em camundongos. Ribeirão Preto, 2017 106p. [Tese Doutorado]. Ribeirão Preto: Faculdade de Odontologia de Ribeirão Preto da Universidade de São Paulo; 2017.

\section{RESUMO}

O conhecimento dos eventos biológicos que ocorrem no periápice dos dentes com necrose pulpar se torna importante para compreender o desenvolvimento das lesões periapicais. Muitas são as moléculas e mediadores que participam na instalação da lesão periapical, a partir da infecção bacteriana que ocorre no interior dos canais radiculares. Assim, o objetivo do presente trabalho foi avaliar moléculas do sistema imune inato, da osteoclastogênese e metaloproteinases em lesões periapicais (LP) induzidas experimentalmente em camundongos knockout e wild type. Para esse objetivo, o presente estudo foi dividido em dois trabalhos distintos. O primeiro teve como objetivo avaliar a expressão de metaloproteinase 2 (MMP2) e metaloproteinase 9 (MMP9) durante a progressão da LP em camundongos knockout para TLR2 (TLR2 KO) e MyD88 (MyD88 KO), em comparação com camundongos wild type (WT). O segundo estudo avaliou a correlação da expressão gênica e imunomarcação de RANK, RANKL, OPG, TLR2 e MyD88 durante a progressão da LP em camundongos WT. No primeiro estudo lesões periapicais foram induzidas em molares inferiores de 54 camundongos TLR2 KO, MyD88 KO e WT ( $n=18 /$ grupo). Após 7, 21 e 42 dias, os animais foram eutanaziados e as mandíbulas foram dissecadas e submetidas a processamento histotécnico. Os cortes histológicos foram submetidos à imunohistoquímica e posteriormente foi avaliada presença ou ausência de MMP2 e MMP9 nos diferentes grupos. No segundo estudo, 35 camundongos WT foram utilizados. As lesões periapicais foram induzidas nos primeiros molares inferiores de ambos os lados. Após 0 (G0), 7 (G7), 21 (G21) e 42 (G42) dias, os animais foram anestesiados e eutanasiados para queas mandíbulas fossem dissecadas e divididas ao meio.O lado direito das mandíbulas foi para o processamento histotécnico, para posterior marcação de RANK, RANKL, OPG, TLR2 e MyD88, por meio da imuno-histoquímica eo lado esquerdo da mandíbula foi utilizado para a extração de RNA, para a determinação da expressão gênica de RANK (Tnfrsf11a), RANKL (Tnfrsf11), OPG ( Tnfrsf11b), TLR2 (TIr2) e MyD88 (Myd88) utilizando quantificação em Tempo Real da Reação da Polimerase em Cadeia (qRT-PCR). Para ambos os estudos, testes paramétricos e não paramétricos foram realizados com nível de significância de 5\%. Foi possível observar, no primeiro estudo, que nos períodos iniciais da progressão da lesão periapical, houve um aumento na imunomarcação de MMP9 nos camundongos 
TLR2 KO e MyD88 KO, quando comparados aos WT, diferente da MMP2 que não se observou nenhum aumento na imunomarcação. No entanto, aos 42 dias observou-se uma redução da imunomarcação de MMP2 e um aumento da MMP9 nos camundongos TLR2 KO. Adicionalmente, no segundo estudo, foi possível observar um aumento da imunomarcação para RANK, RANKL, OPG, TLR2 e MyD88 durante a progressão da lesão periapical $(p<0,05)$. $O$ aumento da expressão de Tnfrsf11 foi diferente entre os grupos G0 e G42, e G21 e G42 ( $p=0,006)$. No entanto, a expressão de Tnfrsf11b foi diferente entre os grupos G0 e G7, G7, G21 e G42, sendo possível observar uma diminuição dessa expressão ao longo do tempo $(p<0,001)$. TIr2 foi mais expresso entre os grupos G0 e G42 ( $p=0,03)$. E a expressão da molécula Myd88 foi estatisticamente significante entre os grupos G0 e G7, G21 e G42 $(p=0,01)$. A razão Tnfrsf11/Tnfrsf11b aumentou durante a progressão da lesão periapical $(p=0,002)$. Também foi possível observar uma correlação moderada entre Myd88 e Rankl $(r=0,42 ; p=0,03)$ e entre Myd88 e Tlr2 $(r=0,48 ; p<0,0001)$. Após as metodologias empregadas e os dados analisados, concluímos que a produção de MMP2 e MMP9 foi modulada por TLR2 e Myd88 durante a progressão da lesão periapical. Além disso, podemos sugerir que existe uma correlação positiva entre 0 sistema RANK/RANKL/OPG e as proteínas do sistema imune inato, TLR2 e MyD88, durante a perda óssea decorrente da infecção bacteriana dos canais radiculares e posterior progressão da lesão periapical.

Palavras-chave: Camundongoswild type, Camundongos knockout, TLR2, MyD88, MMP2, MMP9, Lesão periapical, Sistema RANK, RANKL e OPG 
Barreiros, D.MOLECULAR ASPECTS OF GENESIS AND PROGRESSION OF INDUCED APICAL PERIODONTITIS IN MICE.Ribeirão Preto, 2017. 106p.[Thesis] - School of Dentistry of Ribeirão Preto, University of São Paulo.

\begin{abstract}
Knowledge of the biological events occurring inteeth apex with pulp necrosis becomes important to understand the development of periapical lesions. There are manymolecules and mediators that participate in the installation of the periapical lesion, from the bacterial infection that occurs inside the root canals. Thus, the aim of the present study was to evaluate molecules of the innate immune system, osteoclastogenesis and metalloproteinases in experimentally apical periodontitis (AP) induced in knockout and wild type mice. For this purpose, the present study was divided into two distinct studies. The first one aimed to evaluate the expression of metalloproteinases 2 (MMP2) and metalloproteinases 9 (MMP9) during the progression of AP in TLR2 knockout mice (TLR2 KO) and MyD88 knockout mice (MyD88 KO), compared to wild type mice (WT). The second study evaluated the correlation of gene expression and immunostaining of RANK, RANKL, OPG, TLR2 and MyD88 during LP progression in WT mice. In the first study AP were induced in lower molars of 54 TLR2 KO, MyD88 KO and WT mice ( $n=18$ / group). After 7, 21 and 42 days, the animals were euthanized and the jaws were dissected and submitted to histotechnical processing. The histological sections were submitted to immunohistochemistry and subsequently the presence or absence of MMP2 and MMP9 in the different groups was evaluated. In the second study, 35 WT mice were used. Periapical lesions were induced in the lower first molars on both sides. After 0 (G0) to 7 (G7), 21 (G21) and 42 (G42) days, the animals were anesthetized and euthanized so that the jaws were dissected and divided in half. The right side of the jaws was for the histotechnic processing, for subsequent imunostaining of RANK, RANKL, OPG, TLR2 and MyD88, through immunohistochemistry and the left side of the jaws was used for the extraction of RNA, for the determination of expression of RANK (Tnfrsf11a), RANKL (Tnfrsf11), OPG (Tnfrsf11b), TLR2 (TIr2) and MyD88 (Myd88) using Quantification Real Time of Polymerase Chain Reaction (qRT-PCR). For both studies, parametric and non-parametric tests were performed with significance level of $5 \%$. It was possible to observe in the first study that in the initial periods of AP progression there was an increase in MMP9 immunostaining in TLR2 KO and MyD88 KO mice when compared to WT, different from MMP2 that no increase in immunostaining was observed. However, at 42 days there was a reduction in MMP2 immunostaining and an increase of MMP9 in TLR2 KO mice was
\end{abstract}


observed. Additionally, in the second study, it was possible to observe an increase in the immunostaining for RANK, RANKL, OPG, TLR2 and MyD88 during periapical lesion progression $(p<0.05)$. The increase in Tnfrsf11 expression was different between groups $G 0$ and $G 42$, and G21 and G42 ( $p=0.006$ ). However, the expression of Tnfrsf11b was different between the G0 and G7, G7, G21 and G42 groups, and a decrease in expression over time $(p<0.001)$ was observed. TIr2 was more expressed between the G0 and G42 groups $(p=0.03)$. And the expression of the Myd88 molecule was statistically significant between the G0 and G7, G21 and G42 groups $(p=0.01)$. The Tnfrsf11 / Tnfrsf11b ratio increased during the AP progression $(p=0.002)$. It was also possible to observe a moderate correlation between Myd88 and Rankl $(r=0.42, p=0.03)$ and between Myd88 and TIr2 $(r=$ $0.48, p<0.0001)$. After the methodologies used and the data analyzed, we conclude that the production of MMP2 and MMP9 was modulated by TLR2 and Myd88 during the AP progression. In addition, we can suggest that there is a positive correlation between the RANK / RANKL / OPG system and the proteins of the innate immune system, TLR2 and MyD88, during bone loss due to bacterial infection of the root canals and subsequent progression of the apical periodontitis.

Keywords: wild typemice,knockout mice, TLR2, MyD88, MMP2, MMP9, apical periodontitis, RANK, RANKL e OPG system. 


\section{SUMÁRIO}

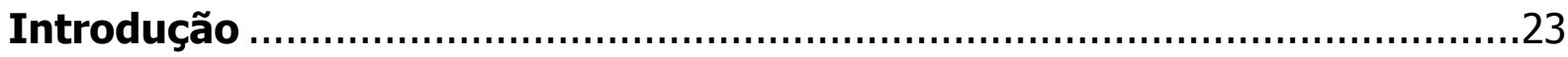

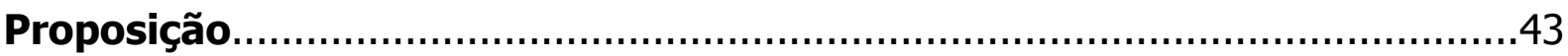

Capítulo 1 MMP2 e MMP9 estão associados com a progressão da lesão periapical e podem ser modulados por TLR2 e MyD88

Capítulo 2 Expressão de RANK, RANKL, OPG, TLR2 e MyD88 durante a progressão da lesão periapical

Conclusão .73

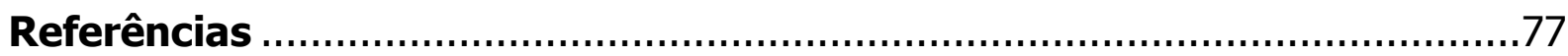

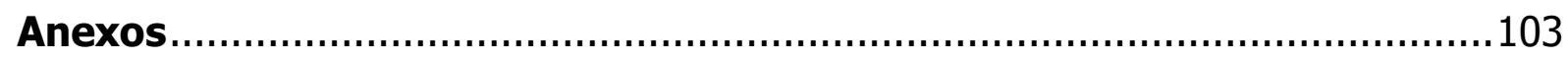



Introdução 



\section{A Lesão Periapical}

As ocorrências de lesões extensas de cárie e de traumatismos dentários com exposição pulpar podem desencadear um processo inflamatório nesse tecido, o qual pode levar à sua necrose. A permanência desse processo resulta na instalação de uma reação infecciosa crônica, com consequente reabsorção óssea na região apical e periapical, tanto em dentes decíduos quanto em dentes permanentes (Graves et al., 2011; De Oliveira, 2013). Desta forma, ocorre a formação da lesão periapical, em dentes não vitais, como o resultado de uma agressão crônica, assintomática, de baixa intensidade, devido à presença de tecido necrótico, o qual é oriundo de uma invasão microbiana no sistema de canais radiculares. Radiograficamente, a lesão periapical aparece como uma área radiolúcida circunscrita na região do ápice dental, podendo ser classificada como cisto ou granuloma periapical, os quais só são diferenciados em um exame microscópico devido à presença ou ausência de um revestimento epitelial em torno da lesão (Neville, 2002). Microscopicamente, durante as fases da lesão periapical pode-se observar um infiltrado inflamatório misto com presença de linfócitos $T$, neutrófilos, linfócitos $B$, macrófagos e plasmócitos (Stashenko e Yu et al., 1989). Em ratos, as lesões periapicais induzidas experimentalmente, apresentam a fase ativa, que se desenvolvem mais rapidamente (0 a 15 dias) e a fase crônica, que é mais lenta nos dias subsequentes. Isso ocorre devido o estabelecimento de uma microbiota anaeróbia e gram-negativa (Stashenko et al., 1994). Nesse processo, o sistema imunológico desempenha um papel importante tentando eliminar o agente agressor. Isto ocorre durante a interação entre os fatores microbianos e de defesa do hospedeiro na interface polpa radicular e ligamento periodontal no periápice do dente, durante a instalação da lesão periapical (Cohen e Buns, 1994; Nair, 2004). Para reverter esse processo infeccioso é necessário o tratamento endodôntico tendo como objetivo principal restabelecer e proteger as estruturas periapicais, devolvendo ao dente sua função na cavidade bucal (Nair, 2003). 


\section{Fatores que influenciam o estabelecimento e a progressão da lesão periapical e o prognóstico do tratamento endodôntico}

Durante o tratamento endodôntico, uma das principais etapas consiste na neutralização dos agentes agressores de origem bacteriana e eliminação da infecção. Para atingir esse objetivo, é necessária a utilização de soluções e materiais irrigadores e obturadores, além da ativação do sistema imune inato e adaptativo do hospedeiro (Nair, 2004; Miyake, 2004; Burgner e Harnden, 2005; Benarafa et al., 2007; Forthal et al., 2007; Helewski et al., 2007; Van Bodegom et al., 2007; Rashid e Ebringer, 2007; Ricucci et al., 2009).Além disso,é necessário, que sejam seguidos princípios técnicos e biológicos que influenciarão diretamente no sucesso ou insucesso do tratamento endodôntico (Espídola et al., 2002; Gabardo et al., 2009; Occhi et al., 2011).

O sucesso e insucesso podem, ainda, estar relacionados a diversos fatores como: o estado geral de saúde do paciente, as condições clínicas do dente, a técnica operacional empregada e habilidade do operador. Tais fatores podem acarretar em inadequação do acesso, perfurações, fratura de instrumentos, sobre obturações, obturações incompletas, reabsorções dentárias, calcificações, baixa qualidade das obturações e micro infiltrações (Lin et al., 1992; Haapasalo et al., 2003; Siqueira et al., 2014).

Cabe ressaltar que, a lesão periapicalé complexa, pois apresenta uma etiologia multifatorial, fazendo com que fatores microbiológicos e fatores inerentes ao hospedeiro também façam parte da sua etiologia.

No início da instalação do processo infeccioso no tecido pulpar, observa-se a prevalência de uma microbiota Gram-positiva, composta principalmente por microorganismos aeróbios, com predomínio de cocos sobre os bacilos e filamentosos (Fabricius et al., 1982). Em seguida, fatores como mudanças no suprimento sanguíneo e na disponibilidade de nutrientes, assim como a subsequente diminuição da tensão de oxigênio e as interações bacterianas, promovem alterações nessa microbiota estabelecendo assim, no sistema de canais radiculares, uma necrose pulpar com formação de uma lesão periapical crônica decorrente de uma infecção polimicrobiana, mista e complexa, com predominância de micro-organismos anaeróbios estritos, particularmente os Gram-negativos (Seltzer e Farber, 1994, 
Assed et al., 1996, Rocha et al., 2008; Cogulu et al., 2008; Mohammadi, 2011). Esses micro-organismos encontram-se localizados não apenas na luz do canal principal e nos túbulos dentinários, mas também nas lacunas cementárias, nas crateras apicais, no biofilme apical e na lesão periapical (Leonardo et al., 2002; 2007; Rocha et al., 2008; Leonardo, 2012).

Os micro-organismos Gram-negativos, além de possuírem diferentes fatores de virulência e gerarem produtos e subprodutos tóxicos aos tecidos apicais e periapicais, contêm a endotoxina em sua parede celular, também conhecida como LPS. Este por sua vez é liberado durante a multiplicação, estresse ou morte bacteriana, exercendo uma série de efeitos biológicos importantes (Rietschel e Brade, 1992; Mc Gee et al., 1992; Haimovich et al., 2010), pois estas estimulam a liberação de mediadores químicos, como interleucina 1-a (IL-1a), interleucina 1- $\beta$ (IL-1 $)$ ), o fator de necrose tumoral (TNF-a) e as linfotoxinas (TNF- $\beta$ ) (Stashenko et al., 1987; Tronstad, 1992; Stashenko, 1992), aumentando a reação inflamatória (Rietschel e Brade, 1992; Matsushita et al., 1999; Roux e Orcel, 2000; Silva et al., 2002) e reabsorção óssea periapical (Stashenko, 1990, Nelson-Filho et al., 2002; Jiang et al., 2003; Silva et al., 2008).

Durante o tratamento endodôntico dos dentes com lesão periapical, além dos micro-organismos, a eficiência das respostas inflamatória e imunológica por eles desencadeadas na tentativa do hospedeiro de neutralizar/destruir esses agentes agressores estão relacionadas com a progressão ou não das lesões periapicais (Burgner e Harnden, 2005; Benarafa et al., 2007; Forthal et al., 2007; Helewski et al., 2007; Van Bodegom et al., 2007; Rashid e Ebringer, 2007). Assim, o insucesso no tratamento endodôntico vem sendo atribuído à persistência desses microorganismos (Nair et al., 1990; Lin et al., 1992; Siqueira e Rôças, 2004; Sakamoto et al., 2008) e de seus subprodutos, devido à resposta insatisfatória do hospedeiro à infecção presente nos canais radiculares (Kerekes e Tronstad, 1979; Orstavik, 1996; Regan e Fleury, 2006; Kandaswamy e Venkateshbabu, 2010).

A defesa do hospedeiro se dá por meio da ativação do sistema imune inato e adaptativo por meio de Receptores de Reconhecimento Padrão (PRRs), os quais são expressos em diferentes compartimentos celulares e que reconhecem patógenos intracelulares e extracelulares. Os PRRs identificam os Padrões Moleculares 
Associados aos Patógenos (PAMPs), que são porções antigênicas estruturalmente conservadas, presentes tanto na superfície quanto na estrutura que compõe os patógenos (Hedayat et al., 2012).

\section{Os receptores Toll-Like ( $T L R S$ ) e a lesão periapical}

Os receptores Toll-Like(TLRs) destacam-se como PRRs efetivos no reconhecimento inicial dos patógenos invasores e no desencadeamento da resposta imunológica do hospedeiro.(Hirao et al., 2009; Kawai e Akira, 2009; Hedayat et al., 2012; van der Vlugt et al., 2014). Estes são receptores transmembrana tipo I, denominados como receptores Toll-like devido a similaridade genética com a proteína Toll em drosófilas (Drosophila melanogaster) (Lemaitre et al., 1997; Medzhitov et al., 1997; Medzhitov, 2001; Underhill e Ozinsky, 2002). Em camundongos foram identificados 13 tipos de TLRs e 11 tipos em humanos (Miggin e O’Neill, 2006; Kawai e Akira, 2009, O’Neill et al., 2013).A maioria dos TLRs (TLRs 1, $2,4,5,6$, e 11) são expressos nas superfícies celulares sendo os demais ( $T L R s$ 3, 7, 8 e 9) expressos em vesículas intracelulares, tais como os endossomos ou lisossomos e o retículo endoplasmático (Takeda e Akira, 2005; Kawai e Akira, 2009; De Nardo et al., 2015).

Os TLRs são classificados de acordo com o reconhecimento de ligantes, o TLR2 que reconhece lipoproteínas/lipopeptídeos de vários patógenos, peptidoglicanos e ácido lipoteicóico de bactérias Gram-positivas (Schwandner et al., 1999; Aliprantis et al., 1999; Dziarski e Gupta, 2000; Takeda e Akira, 2005), além de se heterodimerizar com TLR1 para reconhecer lipopeptídeos triacilados ou com TLR6 para reconhecer lipopeptídeos diacilados (Kawai e Akira, 2009). O TLR4 é estimulado pela lípide A, componente do LPS de bactérias Gram-negativas (Poltorak et al., 1998; Takeda e Akira, 2005). A flagelina bacteriana ativa o TLR5 (Hayashi et al., 2001; Uematsu et al., 2006, 2008). O TLR11 é ativado pela molécula profilin-like do protozoário Toxoplasma gondii (Yarovinsky et al., 2005; Andrade et al., 2013; Koblansky et al., 2013). O TLR3 reconhece RNA de fita dupla, sendo este o principal componente de muitos vírus (Alexopoulou et al., 2001). O RNA de fita simples, também encontrado em vírus estimula o TLR7 e o TLR8 (Heil et al., 2004). O TLR9 é estimulado por porções CpG não metiladas (bactérias e vírus) presentes no DNA 
(Hemmi et al., 2000), além disso, o TLR9 também é estimulado pelo DNA do herpesvírus (Lund et al., 2003; Krug et al., 2004, 2004). O TLR10 não é funcional em camundongos, e os TLR12 e 13 não apresentam função definida no genoma humano (Kawai e Akira, 2009; Gazinelli et al., 2014; Signorino et al., 2014).

Os TLRS são compostos por três principais domínios: 1) o domínio extracelular: formado por uma cadeia rica em leucina; 2) o domínio transmembrana que está incorporado na membrana da célula ou na membrana endossomal; e 3) o domínio citoplasmático (intracelular) ou receptor de Interleucina-1/Receptor TollLike(TIR domain) que se liga ao MyD88. (Janssens e Beyaert, 2003; Carty e Bowie 2010; Avbelj et al., 2011; Dinarello, 2011; Onnis et al., 2012; Wang et al., 2014).

\section{0 receptor Toll-Like-2 (TLR2)}

Conforme já mencionado, o TLR2 é estimulado por lipoproteínas/lipopeptídeos de vários patógenos, peptidoglicanos e ácido lipoteicóico de bactérias Gram-positivas (Babu et al., 2006; Oliveira-Nascimento et al., 2012). Ele participa, também, na transdução de sinal ativada por lipopolissacarídeos (LPS) bacteriano por meio da ligação com a molécula auxiliar MD-2 (proteína de diferenciação mielóide) (Dziarski e Gupta, 2000; Takeda e Akira, 2005). Além disso, foi demonstrado na literatura, a participação do TLR2 na etiopatogenia das lesões periapicais e o seu envolvimento nas respostas ao LPS bacteriano, por meio da expressão de citocinas próinflamatórias, como IL-1, TNF-a, IL-6 e IL-8 (Kirschning et al., 1998; Hoshino et al., 1999).

Em estudo do nosso grupo de pesquisa, animais knockout para TLR2, apresentaram lesões periapicais mais extensas quando comparados com animais wild type, sugerindo o importante papel desse receptor na resposta imune e inflamatória do organismo no combate da infecção dos sistemas de canais radiculares e dos tecidos periapicais (da Silva et al., 2012).

\section{A Molécula Adaptadora MyD88}

A molécula MyD88 é essencial para respostas contra uma ampla variedade de micro-organismos e participa na ativação de quase todos os TLRS (exceto do TLR3). Ela desencadeia a ativação da proteína quinase (Gomes et al., 2012; Deguine et al., 
2014), além disso, a MyD88 desempenha um papel importante no controle da infecção, na ativação imediata do sistema imune inato, na produção de citocinas e na ativação da resposta imune adaptativa em fases tardias (Koh et al., 2010).

A via de sinalização dependente de MyD88 está associada à porção TIR dos TLRs e promove o recrutamento da IRAK-4 (IL-1R associated kinase-4) e facilita a fosforilação da IRAK-1 que, ativada, associa-se ao TRAF6 (TNFR-associated factor G), levando à ativação de duas vias distintas de sinalização (Takeda e Akira, 2004; Deguine et al., 2014). A primeira via leva à ativação de fatores de transcrição AP1(activator protein-1) por meio da ativação de MAPK (mitogen-activated protein kinases), enquanto a segunda ativa o complexo TAK1/TAB (transforming growth factor $\beta$-activated kinase 1/ TAK1-binding protein), que potencializa a atividade do complexo IKK (IKB kinase), o qual induz a fosforilação e subsequente degradação de IKB (inhibitor of $\kappa B$ ), causando a translocação nuclear do fator de transcrição NF-kB (Factor nuclear kappa B) e sua ligação em regiões-alvo do DNA. Estes fatores de transcrição, NF-KB e AP-1 induzem a expressão de mediadores bioquímicos importantes, como citocinas pró-inflamatórias, quimiocinas, moléculas de adesão, além de moléculas co-estimuladoras e espécies reativas de oxigênio. Paralelamente, a avaliação de moléculas estruturalmente relacionadas com a MyD88 levou à identificação de uma segunda porção do TIR que contém a molécula TIRAP (TIR domain-containing adaptor protein) ou Mal(MyD88-adaptor-like), que é essencial para a sinalização dependente de MyD88 via TLR2 (Lye et al., 2004; Takeda e Akira, 2005; Verstak et al., 2009; Mukherjee et al., 2016).

\section{A relação entre TLRs e MyD88 - estudos em modelos animais na área da Odontologia}

Os modelos animais têm sido utilizados na pesquisa científica e na investigação de doenças humanas, com o propósito de entender melhor os processos fisiológicos e patológicos.(Heywood, 1987; Ribeiro et al., 1995; Salén, 1995; Snitkoff, 2004; Manning et al., 2015; Faggion et al., 2015). O animal escolhido usualmente deve possuir equivalência taxonômica para reagir à doença de uma maneira que se assemelha à fisiologia humana (Fagundes e Taha, 2004; Kariet al., 2007; Chakraborty et al., 2009). Dessa forma o animal mais utilizado atualmente para 
estudar as causas, os mecanismos e a terapêutica das doenças humanas, é o camundongo. Isto ocorre devido a sua alta similaridade genética com os humanos, por seu genoma ser facilmente manipulado, ser de pequeno porte, muito prolífero, ter período de gestação e ciclo de vida curto e ser de fácil domesticação e manutenção (Santos, 2002). Além disso, em relação especificamente a Odontologia, os primeiros molares possuem sistemas de canais radiculares semelhantes aos molares humanos, o que torna possível o estudo de patologias endodônticas (Thomaz et al., 2006; Dangelo e Fattini, 2007; Kardong, 2010;).

Nesse sentido, Mutoh et al. (2009) objetivaram investigar a relação entre o sistema imune inato, a defesa do tecido pulpar e as expressões de TLR2 e TLR4, utilizando camundongos com imunodeficiência combinada severa (SCID). Para esta avaliação, foi realizada a indução da pulpite nos primeiros molares inferiores dos camundongos. Os autores observaram que a expressão gênica de TLR2 e TLR4 estava presentes nas polpas contaminadas por micro-organismos bucais após a indução de pulpite. Na análise morfológica, células positivas para TLR2 e TLR4 constituíram-se principalmente de macrófagos, células polimorfonucleares, odontoblastos e células dendríticas na interface polpa-dentina na fase inicial da pulpite. Os autores sugeriram que a expressão de TLR2 e TLR4 pode ser desencadeada por uma infecção bacteriana em pulpite irreversível sem a necessidade de uma resposta imune adaptativa.

Chokechanachaisakul et al. (2010) avaliaram o ligamento periodontal de dentes de ratos com lesão de furca em molares submetidos a pulpotomia, com ou sem selamento da cavidade. A função dos $T L R s$ foi avaliada por meio das análises de expressão gênica e imuno-histoquímica. Os autores observaram maior número de células que expressaram TLR2 e TLR4 na região de furca no grupo de pulpotomia sem o selamento coronário. Estes resultados sugerem o envolvimento do mecanismo imune inato juntamente com TLR2 e TLR4 e a ativação precoce de células que apresentam o antígeno na inflamação induzida na região de furca.

Avaliando lesões periapicais experimentalmente induzidas em camundongos, nosso grupo de pesquisa demonstrou que a ausência de TLR2, em animais knockout, desencadeou o desenvolvimento de lesões periapicais significantemente maiores quando comparados com os animais wild type, demonstrando a importância desse 
receptor na resposta imune e inflamatória do organismo no sentido de combater a infecção do sistema de canais radiculares e dos tecidos periapicais (Da Silva et al., 2012).

Outro estudo do nosso grupo de pesquisa, avaliando lesões periapicais experimentalmente induzidas em camundongos knockout para MyD88, concluiu que na ausência do MyD88, os animais apresentaram lesões periapicais mais extensas, com um infiltrado inflamatório mais intenso e com maior número de neutrófilos quando comparados a animais wild type. Este resultado demonstra o importante papel dessa molécula na resposta imune e inflamatória do organismo no combate à infecção de origem endodôntica (Bezerra da Silva et al., 2014).

O estudo recente de Rider et al. (2016), utilizaram camundongos knockout para TLR2, duplamente knockout para TLR2/TLR4 e wild type. Os autores demonstraram que os camundongos knockout para TLR2 apresentaram lesões periapicais maiores quando comparados aos outros grupos experimentais. Isto ocorreu devido a ativação da via de transdução de sinal pelo TLR4 o qual resultou na elevação do NF-kB e na produção de citocinas pró-inflamatórias. Esta ativação resultou na elevação da expressão de um co-receptor de TLR4, denominado de cluster de diferenciação 14 (CD-14). Os autores sugerem que TLR2, TLR4 e CD14 podem ser fatores chave na regulação da infecção polimicrobiana dentoalveolar e posterior destruição de tecidos.

\section{Estudos clínicos da participação dos TLRs e MyD88 nas patologias da cavidade bucal}

O mecanismo TLRS/MyD88 já foi previamente estudado em Odontologia, com destaque principalmente nas pesquisas realizadas na Periodontia e na Endodontia. Os TLRS estão fortemente expressos em múltiplos tipos celulares associados às infecções de origem endodôntica e periodontal como monócitos/macrófagos, granulócitos, fibroblastos, precursores de osteoclastos, células mesenquimais, mielóides e não hematopoiéticas (Bar-Shavit, 2008; Hirao et al., 2009; Chiron et al., 2009; Cooper et al., 2014).

$\mathrm{Na}$ Periodontia, estudos recentes demonstraram a importância desses receptores no reconhecimento e combate de micro-organismos relacionados à 
doença periodontal. Yumoto et al. (2015) evidenciaram que a aplicação de 2metacriloiloxietil fosforilcolina (MPC), um enxaguatório bucal, reduziu significantemente a adesão de Porphyromonas gingivalis às células epiteliais periodontais e a subsequente resposta imune inata mediada por TLR2.

Ghaderi et al. (2014) avaliaram os padrões de expressão de alguns dos TLRs e da MyD88 em tecidos gengivais saudáveis e tecidos gengivais com gengivite e periodontite crônica. $\mathrm{Na}$ análise da expressão gênica, constatou-se níveis elevados de MyD88 na periodontite, entretanto, não foi observada diferença nos níveis de TLR2. Esses achados propõe que MyD88 pode ter um papel fundamental na patogênese da doença periodontal.

Outro estudo, realizado por Promsudthi et al. (2014), objetivou determinar se os receptores TLR2 e TLR4 estavam envolvidos na relação entre periodontite crônica e diabetes. Os autores concluíram que tanto a hiperglicemia quanto a periodontite crônica influenciam a expressão de TLR2 e TLR4 no tecido gengival. As diferenças na expressão de TLR2 e TLR4 pode contribuir para uma resposta inflamatória periodontal mais exacerbada, estimulando o início e progressão da doença.

Já na Endodontia, Desai et al. (2011) caracterizaram a expressão de TLR2, por imuno-histoquímica, nas células presentes em lesões periapicais refratárias. Os autores sugeriram que a presença de células que expressam TLR2 em granulomas e cistos periapicais fornece evidência adicional de que os cistos periapicais são mantidos, em parte, pelo sistema imunológico por meio da reação de antígenos bacterianos.

Özan et al.(2016) avaliaram o papel das variações genéticas dos receptores Toll-like (TLR) 2, 3 e 4 na susceptibilidade genética à patologia periapical. Pacientes que necessitavam de tratamento de canal radicular foram divididos em 2 grupos: com e sem presença de lesão periapical. Amostras de sangues foram coletadas para determinar ummarcador genético que poderia identificar pessoas com maior risco de patologia periapical. Os autores concluíram que pacientes com polimorfismo do gene TLR3 podem ser mais susceptíveis a patologias periapicais. 


\section{Metaloproteinases (MMP's) na lesão periapical}

As metaloproteinases (MMPs) são uma importante família de metaloendopeptidases que são capazes de degradar componentes da matriz extracelular (ECM), incluindo a matriz óssea (Everts et al., 1992; Tsuji et al., 2009). Os membros da família de MMPs são divididos em colagenases (MMP-1, -8 e -13), gelatinases (MMP-2 e -9), estromelisinas (MMP-3 e -10), MMPs de membrana (MMP-14, -15, -16, -17 e -24) e outros (MMP-7, -12, -19, -20, -21, -22 e -23) (Curran e Murray et al., 2000).

A regulação da função das MMPs ocorre em diferentes níveis. A expressão de mRNA das MMPs está sob controle dependente do tipo de célula e geralmente em tecidos sadios são expressas em baixos níveis, podendo aumentar rapidamente quando os tecidos sofrem remodelação, como em casos de inflamação, cicatrização de feridas e no câncer. As MMPs são sintetizadas como enzimas latentes que podem estar presentes no interior de células inflamatórias, mas são mais frequentemente encontradas isoladas e ligadas à superfície celular ou a outras proteínas na superfície celular ou dentro do ECM (Nagase e Woessner, 1999; Coussens et al., 2002; Sorsa et al., 2011).

As MMPs estão diretamente associadas aos níveis de inflamação e desempenham um papel importante na remodelação e reabsorção óssea (Hill et al., 1994). Elas são secretadas em forma de proenzima, requerem ativação extracelular e são reguladas por inibidores secretados endogenamente (inibidor tecidual de metaloproteinases (TIMPs)) (Hill et al., 1994). Estudos in vitro e in vivo descrevem o papel das MMPs na reabsorção óssea e na metástase óssea (Chang et al., 2002; Godefroy et al., 2014). Os mecanismos moleculares da reabsorção óssea envolvem clivagem proteolítica de substratos e subsequente ativação de fatores pró metastáticos tais como TGF- $\beta$ (fator de transformação do crescimento beta), IGFs (fator de crescimento semelhante a insulina) e VEGFs (fator de crescimento endotelial vascular) e ativação final da via RANK/RANKL/OPG. Já na matriz óssea, que é composta principalmente de colágeno fibrilar tipo I mineralizado, as MMPs são capazes de clivar o colágeno, não-desnaturado com longas hélices triplas ininterruptas (Guise, 2009). 
As MMPs são os principais agentes na degradação do colágeno durante a destruição do tecido periodontal (Birkedal-Hansen et al., 1993; van der Zee et al., 1996; Chang et al., 2002; Nishikawa et al., 2002; Rossa-Junior et al., 2005). Níveis elevados de MMPs nesses tecidos promovem um desequilíbrio entre a produção e a degradação do colágeno, causando perda de inserção dentária (Hernandez et al., 2006; Sorsa et al., 2006).

Vários estudos têm demonstrado que as MMPs também participam na degradação da polpa e da inflamação periapical (Wahlgren et al., 2002; Cao et al., 2005; Corotti et al., 2009; Sorsa et al., 2011; Li et al., 2012). As concentrações de MMP1, MMP2 e MMP3 são significativamente maiores durante a destruição do tecido pulpar e desenvolvimento das lesões periapicais (Shin et al., 2002). A MMP8 apresenta-se na polpa inflamada e tecido periapical e tem papel na inflamação desses tecidos (Wahlgren et al., 2002). MMP2 e MMP9 estão aumentadas no fluido gengival de dentes com lesões periapicais, bem como em polpas inflamadas em comparação com amostras saudáveis (Belmar et al., 2008; Accorsi-Mendonça, 2013).

MMP2, também denominada de gelatinase $A$, é importante para o turnover da matriz extracelular (ECM), clivando preferencialmente os colágenos tipos IV, V, VII e XI (Price et al., 2001). MMP9 (gelatinase B) é uma enzima multidomínio que funciona em doenças inflamatórias e neoplásicas agudas e crônicas. É essencial para iniciar o processo de reabsorção óssea removendo a camada de colágeno da superfície óssea para que a desmineralização possa acontecer (Delaissé et al., 2000).

Carneiro et al. (2009) determinaram a expressão de MMP9 em lesões periapicais em humanos. As lesões foram divididas em lesões de periodontite apical epitelializada e não epitelializada e foram submetidas a imuno-histoquímica e expressão gênica. Os autores concluíram que a MMP9 está associada à degradação da matriz extracelular em processos patológicos periapicais.

Corotti et al. (2009) analisaram a expressão de MMP2 e 9 durante o desenvolvimento da lesão periapical em ratos. Os autores sugerem que a MMP2 e 9 desempenham um papel crítico no desenvolvimento da lesão periapical, provavelmente envolvendo a degradação da ECM durante a fase inicial do desenvolvimento da lesão. 
Wan et al. (2014) avaliaram a progressão da lesão periapical em camundongos knockout para MMP9 comparados com camundongos wild type. Foi analisado o tamanho da lesão periapical por microtomografia computadorizada, o número dos osteoclastos e a expressão de RANK, RANKL, OPG, IL-1 $\beta$, TNFa, MMP2 e 8. Os autores concluíram que camundongos knockout para MMP9 desenvolveram lesões periapicais maiores com grande resposta inflamatória, indicando um papel importante para a MMP9 na resposta imune e inflamatória do hospedeiro durante a progressão da lesão periapical.

Analisando o reimplante dentário, Leone et al. (2015) avaliaram as mudanças na polpa de pré-molares humanos reimplantados. Todos os dentes foram submetidos a análise histológica e os níveis de MMP2 e MMP9 foram analisados empregando imuno-histoquímica. Os resultados mostraram degradação da ECM, infiltrado de células inflamatórias, perda na interface dentina-polpa e perda de odontoblastos no tecido pulpar. Isto foi acompanhado por aumento ao longo do tempo de MMP9 e uma diminuição de MMP2, demonstrando que a apoptose de odontoblastos aumentou ao longo do período experimental.

Martinho et al. (2016) tiveram como objetivo investigar os níveis de MMP1, 2 e 9; TIMP1 e 2 e suas respectivas formas complexas (MMP1/TIMP1, MMP1/TIMP2, MMP2/TIMP1, MMP2/TIMP2, MMP9/TIMP1, and MMP9/TIMP2) na lesão periapical, além de quantificar os níveis de LPS. Os autores coletaram líquido intersticial do interior da lesão periapical com pontas de papel absorvente introduzidas no canal $2 \mathrm{~mm}$ além do forame, após a instrumentação. Já a endotoxina foi coletada também com cones de papel absorvente antes da instrumentação do canal radicular. Os resultados desses autores demonstram a presença de níveis elevados de MMP9, seguido pela MMP2 e 1. O TIMP1 também apresentou níveis elevados quando comparado ao TIMP2. Já as endotoxinas presentes nos canais radiculares foram positivamente correlacionadas com quantidades maiores de MMP9. Os autores concluíram que MMP1, 2 e 9, os TIMP1 e 2 e suas formas complexas (MMP/TIMP) estão envolvidos com lesão periapical. 


\section{Interação entre MMP2 e 9, TLR2 e MyD88}

Recentes estudos na área médica tem demonstrado uma associação entre MMP2 e 9 e proteínas do sistema imune inato como o TLR2 e MyD88 (Bai et al., 2014; Godefroy et al., 2014; Ahmad et al., 2014; Hu et al., 2014; Wang et al., 2015; Shihab et al., 2015; Min et al., 2015).

Estudos demonstraram que TLR2 funciona como um receptor não apenas para padrões moleculares associados a patógenos, mas também para moléculas endógenas liberadas de tecidos ou células danificadas (Ohashi et al., 2000; Vabulas et al., 2002; Huang et al., 2009). No entanto, a MMP2 parece funcionar de forma semelhante aos sinais endógenos, que são liberados em resposta à infecção ou remodelação de tecido, conhecidos como "alarmins", produzidos por vários tipos de células e que podem ativar e recrutar os receptores da resposta imune inata e adaptativa do hospedeiro (Oppenheim et al., 2007). Godefroy et al. (2014) demonstraram que a MMP2 funciona como um sinal endógeno ativando TLR2, fazendo com que haja a modulação de respostas inflamatórias em células dendriticas.

É conhecido também que expressões de MMP9 estão relacionadas à sinalização de TLR, por exemplo, em infecções por influenza (Bradley et al., 2012). Já Hu et al. (2014) demonstraram que o glioma, um tumor de células gliais, está associado a expressão de MMP9 em células micróglias sendo regulado por TLR2. Peptidoglicanos induzem a expressão de IL-6 e MMP9 em micróglia e neutrófilos, respectivamente (Wang et al., 2005; Lin et al., 2011). Shihab et al. (2015) descreveram que a neutralização de TLR2 e a deficiência de MyD88 bloquearam a ativação de NF-kB/AP-1 juntamente com a inibição da expressão de MMP-9. Outro estudo demonstrou que TLR2 regula a expressão e atividade de MMP9 em astrócitos no sistema nervoso central ativados por patógenos (Min et al., 2015).

Já na Odontologia, mais especificamente na Periodontia, uma revisão sistemática analisando-se o polimorfismo de TLR2 e 4 e de MMP1 e 9 confere susceptibilidade à periodontite em população etnicamente diferentes. Os autores demonstraram que existe uma falta de associação entre os polimorfismos de TLR2, 4, MMP9 e periodontite, mas observa-se uma associação entre o genótipo de MMP1 e a periodontite em pessoas de etnia asiática (Song et al., 2013). No entanto, na 
Endodontia não existem estudos demonstrando a associação entre MMP2, MMP9, TLR2 e MyD88.

\section{Sistema RANK/RANKL/OPG durante a progressão da lesão peripical}

Na literatura específica, há duas décadas, avanços significativos nos estudos na área de biologia óssea determinaram a identificação e caracterização do sistema RANK/RANKL/OPG (Khosla, 2001). Muitos pesquisadores tem avaliado este sistema durante a progressão da lesão periapical (Kawashima et al., 2007; Menezes et al., 2008; da Silva et al., 2012; Belibasakis et al., 2012; Bezerra da Silva et al., 2014; Rechenberg et al., 2014; Armada et al., 2015; Estrela et al., 2016; Carneiro et al., 2017).

Este sistema é composto por três proteínas importantes, que fazem parte do processo de remodelação óssea. ORANK (receptor ativador do fator nuclear kappa B) é uma proteína da superfície celular que está presente em pré-osteoclastos, macrófagos e osteoclastos maduros. O seu ligante, RANKL (ligante do receptor ativador do fator nuclear kappa beta)é uma molécula pertencente a família do fator de necrose tumoral (TNF) que se liga diretamente ao RANK sendo responsável pela indução da reabsorção óssea. Outro componente desse sistema é a OPG (osteoprotegerina), esta por sua vez é semelhante aos receptores de TNF, sendo considerado o inibidor natural da diferenciação dos osteoclastos, que se liga ao RANKL impedindo assim a ligação RANK/RANKL, regulando o processo de reabsorção óssea(Yasuda etal., 1998; Alliston et al., 2002; Theill et al., 2002).

O sistema RANK/RANKL/OPG é um regulador chave da remodelação óssea e essencial para a diferenciação e ativação de osteoclastos (Theill et al., 2002; Wittrant et al., 2004). A produção de RANKL e OPG por vários tipos de células é controlada por estímulos locais e sistêmicos, incluindo hormônios, mediadores inflamatórios e produtos bacterianos (Lerner, 2006; Harokopakis-Hajishengallis, 2007). A eficiência da atividade de RANKL na diferenciação de osteoclastos e na reabsorção óssea está fortemente associada aos níveis do seu inibidor natural, a OPG. Portanto, o estudo concomitante da expressão dessas duas moléculas em locais de reabsorção óssea é importante, pois avaliam especificamente a razão RANK/OPG (Belibasakis et al., 2013). 
O sistema RANK/RANKL/OPG está relacionado a diversas doenças imunológicas e esqueléticas caracterizadas por reabsorções ósseas incluindo osteoporose pós-menopausa, osteoporose induzida por corticóides, metástases ósseas, artrites inflamatórias (Teng et al., 2000; Lener UH, 2004), periodontite (Crottti et al., 2003), durante o movimento ortodôntico (Shiotani et al., 2001), durante o desenvolvimento do germe dental (Suzuki et al., 2004), em algumas lesões osteolíticas no esqueleto facial (Tay et al., 2004) e em lesões periapicais (Menezes et al., 2006; Kawashima et al., 2007; Menezes et al., 2008; da Silva et al., 2012; Belibasakis et al., 2013; Rechenberg et al., 2014; Bezerra da Silva et al., 2014; Armada et al., 2015; Estrela et al., 2016; Carneiro et al., 2017).

Um estudo em modelo animal teve como objetivo elucidar a cinética de RANK, RANKL, OPG e expressões de citocinas (IL- $1 a, I L-1 \beta, I L-10$, TNF-a e $\beta$-actin) em lesões periapicais induzidas experimentalmente. Os autores concluíram que a expressão de RANKL e citocinas pro-inflamatórias estão correlacionadas com o aumento da lesão periapical (Kawashima et al., 2007).

Liu e Peng (2013) avaliaram a presença do fator inibidor da migração de macrófagos (MIF) em lesões periapicais e compararam a sua expressão com RANKL com a reabsorção óssea em diferentes estágios das lesões periapicais em ratos Wistar. Após a imuno-histoquímica, os autores concluíram que o MIF estava associado à diferenciação dos osteoclastos nas lesões periapicais, contribuindo para a patogênese das lesões periapicais pela indução da proteína RANKL.

Em um estudo em humanos, Menezes et al. (2006) avaliaram a expressão de RANKL e OPG associado a destruição óssea em cistos e granulomas periapicais humanos. Os autores concluíram que RANKL e OPG estavam presentes em cistos e granulomas periapicais, sugerindo um forte envolvimento dos mesmos no desenvolvimento da lesão periapical.

Outro estudo analisando cistos radiculares avaliou por meio de imunohistoquímica a expressão de RANK, RANKL e OPG no infiltrado inflamatório, no epitélio hiperplásico e em dois tecidos conjuntivos, o que estava próximo e o que estava distante do epitélio hiperplásico. Os resultados desse estudo reforçaram a participação de RANK, RANKL e OPG em doenças inflamatórias perirradiculares. Além disso, os cistos perirradiculares permeados de infiltrado inflamatório crônico 
apresentaram maior expressão de RANKL do que de OPG, sustentando a evidência de que nessas lesões pode haver maior estimulação da osteólise (Armada et al., 2015).

Estrela et al. (2016) analisaram o perfil de células imunoinflamatórias e a expressão de RANKL e OPG em lesões periapicais persistentes após o retratamento endodôntico. As lesões periapicais persistentes foram removidas de 20 pacientes e submetidas a análise imuno-histoquímica e de expressão gênica. Os autores concluíram que as lesões periapicais persistentes são lesões biologicamente ativas que demonstram potencial de reabsorção óssea e são caracterizadas por um perfil celular imunoinflamatório o que sugere um ambiente supressor e regulador favorável ao comportamento clínico crônico.

\section{Relação entre o sistema RANK/RANKL/OPG, TLR2 e MyD88}

Infecções inflamatórias bacterianas podem causar doenças ósseas como osteomielite, osteíte, artrite reumatóide, periodontite e lesões periapicais, e trabalhos recentes sugerem que os PAMPs regulam a osteoclastogênese dessas desordens ósseas (Henderson e Nair, 2003; Sato et al., 2004; Ukai et al., 2008; Yang et al., 2009; Zhang et al., 2011; Milanova et al., 2014; Leite et al., 2015; Kassem et al., 2016). Como dito anteriormente, as PAMPs estão presentes tanto na superfície quanto na estrutura que compõe os patógenos. Os mesmos são reconhecidos pelos PRRs, como o TLR2, que são expressos em diferentes compartimentos celulares e que reconhecem patógenos intracelulares e extracelulares (Hedayat et al., 2012).

Muitos autores tem reportado que o TLR2 é crucial para a perda óssea inflamatória em resposta a infecções bacterianas, principalmente bactérias Gramnegativas como a Porphyromonas gingivalis (Burns et al., 2006; Gibson et al., 2007; Zhang et al., 2011), em doenças periodontais. Kassem et al.(2016), demonstraram que TLR2 mediado por Staphylococcus aureus induz a reabsorção óssea e a osteoclastogênese por meio de RANKL.

Da Silva et al. (2012) demonstraram que camundongos knockout para TLR2 apresentaram, por meio da histoenzimologia para a atividade TRAP, um maior número de osteoclastos aos 7, 21 e 42 dias quando comparados aos camundongos wild type. Outro achado foi, por meio da imuno-histoquímica, a presença de RANKL 
durante toda a progressão da lesão periapical, no entanto, a OPG foi detectada aos 21 e 42 dias, enquanto que RANK só foi imunomarcado nos camundongos wild type.

Bezerra da Silva et al. (2014) utilizando animais knockout para MyD88, analisou a progressão da lesão periapical aos 7, 21 e 42 dias. Os autores concluíram que os animais knockout para MyD88 desenvolveram lesões periapicais maiores quando comparados aos animais wild type. Além disso, foi observada maior quantidade de osteoclastos na lesão periapical e o sistema RANK/RANKL/OPG foi detectado, por meio da imuno-histoquímica, em todos os períodos experimentais.

Na Odontologia, são escassos os estudos que demonstram uma interação entre o sistema RANK/RANKL/OPG e TLR2 e MyD88 (Liu et al., 2010; da Silva et al., 2012; Lin et al., 2013; Bezerra da Silva et al., 2014), ao contrário de outras áreas biológicas onde os estudos estão avançados relacionando essas moléculas (Sato et al., 2004; Ukai et al., 2008; Yang et al., 2009; Zhang et al., 2011; Leite et al., 2014; Milanova et al., 2014; Kassem et al., 2016).

No entanto, estudos com modelos animais são de fundamental importância para auxiliar na identificação de fatores moleculares envolvidos com a resposta do hospedeiro à diferentes processos patológicos na cavidade bucal. E o conhecimento dos aspectos moleculares envolvidos na resposta do hospedeiro à lesão periapical e ao tratamento endodôntico poderá ter impacto direto nos estudos realizados com modelos humanos bem como em estudos futuros nas áreas de terapêutica odontológica e farmacogenética. Avanços científicos nessas áreas permitirão alterações em protocolos de tratamento com impacto positivo no prognóstico clínico assim como na qualidade de vida da população. 

Proposição 

Com base no exposto o objetivo geral do presente trabalho foi analisar os aspectos moleculares de MMPs, TLR2, MyD88 e do sistema RANK/RANKL/OPG durante a progressão da lesão periapical em camundongos knockout e wild type.

\section{Objetivos específicos:}

1. Avaliar a expressão de MMP2 e MMP9 durante a progressão da LP em camundongos knockout para TLR2 (TLR2 KO) e MyD88 (MyD88 KO), em comparação com camundongos wild type (WT).

2. Avaliar a correlação da expressão gênica e imunomarcação de RANK, RANKL, OPG, TLR2 e MyD88 durante a progressão da LP em camundongos. 



\section{Capítulo 1}

$\mathcal{M M P}_{2}$ e $\mathcal{M M \mathcal { M }}_{9}$ estão assocíados com a progressão da lesão períapical e podem ser modulados por $\mathcal{T} \mathcal{L} 2$ e $\mathcal{M}$ y $\mathcal{D} 88$ 



\section{Introdução}

A lesão periapical (LP) é uma alteração inflamatória nos tecidos periapicais (Kakehashi et al., 1965) que resulta na reabsorção óssea (Kabak et al., 2005). A associação da infecção microbiana persistente no sistema de canais radiculares (Kakehashi et al., 1965), à progressão destes micro-organismos da polpa dentária para o forame apical e a ausência de resposta imunológica do hospedeiro levam à LP. Durante a LP, às células do tecido periapical expressam mediadores inflamatórios, citocinas pró-inflamatórias e fatores de crescimento por meio da resposta imune inata e adaptativa do hospedeiro (Lin et al., 2007).

Receptores Toll-like ( $T L R s$ ) são receptores transmembrana tipo I que apresentam um papel fundamental no sistema imune inato e adaptativo do hospedeiro. Os TLRs reconhecem os padrões moleculares associados aos patógenos (PAMPs), como os componentes virais e bacterianos e mediadores endógenos como proteínas (Takeda e Akira, 2005) e citocinas inflamatórias (Kawai e Akira, 2006). Estudos prévios em animais (da Silva et al., 2012; Bezerra da Silva et al., 2014; Rider et al., 2016) e em humanos (Leonardi et al., 2015; Özan et al., 2016) tem demonstrado que os TLRs desempenham um importante papel na patogênese da LP.

O receptor toll-like 2 (TLR2) reconhece lipoproteínas/lipopeptídeos de diferentes patógenos, peptidoglicanos e ácido lipoteicóico de bactérias Gram-positivas, que desencadeiam sinais inflamatórios em células imune inatas (Takeda e Akira, 2005; Kawai e Akira, 2009; van der Vlugt et al., 2014). O reconhecimento de uma invasão microbiana através dos $T L R S$, incluindo TLR2, desencadeia a ativação de vias de sinalização, resultando no recrutamento de várias proteínas adaptadoras para o domínio receptor de Interleucina-1/Receptor Toll-Like (TIR). O fator de diferenciação mielóide 88 (MyD88) é uma molécula adaptadora comum a quase todos os TLRs exceto o TLR3 (Kawai e Akira, 2009) e desencadeia a ativação da proteína quinase e dos fatores de transcrição que estimulam a expressão dos genes que estão envolvidos com a resposta inflamatória (Gomes et al., 2012). Um estudo recente demonstrou que camundongos knockout para MyD88apresentaram LP maiores, sugerindo o papel desse fator na progressão da LP (Bezerra da Silva et al., 2014).

As metaloproteinases da matriz (MMPs) são em sua maioria enzimas secretadas por fibroblastos ou por células da família dos fibroblastos como 
condroblastos e osteoblastos (Alberts et al., 1997; Mott e Werb, 2004).Além disso, pertencem a uma família de enzimas proteolíticas dependentes de zinco e cálcio que são conhecidas por degradarem a maioria dos componentes da matriz extracelular (ECM) (Murphy, 1995). As MMPs estão fortemente associadas com os níveis de inflamação e desempenham um papel importante na remodelação e reabsorção óssea (Hill et al., 1994). A MMP2 participa na remodelação e resolução da lesão tecidual (Brooks et al., 1998) e no reparo da infecção (Lima et al., 2012). Por outro lado, a MMP9 é uma enzima multidomínio e atua em condições inflamatórias agudas e crônicas (Buzoglu et al., 2009),sendo essencial para o início do processo de reabsorção osteoclástica por meio da remoção da camada colagenosa do tecido ósseo (Delaissé et al., 2000).

Algumas evidências sugerem que as MMPs estão envolvidas com 0 desenvolvimento da LP (Carneiro et al., 2009; Paula-Silva et al., 2010; Menezes-Silva et al., 2012; Campos et al., 2015) e desempenham um papel importante na destruição do tecido pulpar e periapical durante o processo de inflamação (Carneiro et al., 2009). Em particular, a expressão de MMP2 e MMP9 tem sido relatada consistentemente em estudos sobre a LP (Carneiro et al., 2009; Paula-Silva et al., 2010; Menezes-Silva et al., 2012; Campos et al., 2015).

Alguns estudos demonstram a interação entre TLR2 e MMPs. TLR2 regula a MMP2 e a MMP9 em células-tronco do glioma (Wang et al., 2015) e regula a MMP9 em células monocíticas (Shihab et al., 2015). Embora a interação entre essas proteínas tenha sido previamente investigada em outras áreas do conhecimento, seu papel na progressão da LP ainda é inexplorado. Portanto, o objetivo deste estudo foi avaliar a expressão de MMP2 e MMP9 durante a progressão da LP em camundongos knockout para TLR2 (TLR2 KO) e MyD88 (MyD88 KO), em comparação com camundongos wild type (WT).

\section{Material e Métodos}

\section{Animais}

Os procedimentos animais foram realizados de acordo com as diretrizes éticas da Comissão de Ética no Uso de Animais da Universidade de São Paulo - Campus de 
Ribeirão Preto, após a aprovação do projeto de pesquisa (Processo no 11.1.91.53.0 (Anexo A) e 2014.1.911.58 (Anexo B)).

Após a realização do cálculo amostral baseado no estudo de Wan et al., 2014 e utilizando o software SigmaPlot 12.0 (Systat Software Inc., Canadá- EUA)foram utilizados camundongos WT machos da linhagem C57BL/6 ( $\mathrm{n}=18$ animais), TLR2 KO da linhagem B6.129-TLR2 ${ }^{\text {tm1 kir/j }}$ ( $n=18$ animais) e MyD88 KO da linhagem C57BL/6 ( $\mathrm{n}=18$ animais), com idades entre 6 a 8 semanas. Os camundongos WT foram obtidos do Biotério Central da Universidade de São Paulo - Campus de Ribeirão Preto e os camundongos TLR2 KO e MyD88 KO foram fornecidos pelo Biotério de Genética da Faculdade de Medicina do Ribeirão - USP, provenientes do The Jackson Laboratory (Bar Harbor, Maine, EUA).

\section{Indução da $L P$}

Os camundongos foram anestesiados por meio de uma injeção intramuscular de cloridrato de ketamina a 10\% (150 mg/kg - Agener União Química Farmacêutica Nacional S/A, Embu-Guaçu, São Paulo, Brasil) e 2\% de cloridrato de xilazina (7,5 mg/kg - Dopaser, Laboratórios Calier, SA, Barcelona, Espanha) e, posteriormente foram montados em uma mesa de retração mandibular.

Para o acesso à câmara pulpar dos primeiros molares inferiores, foram utilizadas brocas esféricas de aço inoxidável de tamanho 1/4 (GDK Densell Dental Technology, Buenos Aires, Argentina) montados em motor de baixa rotação. Após a abertura coronária, os canais radiculares foram localizados com uma lima endodontica tipo K estéril número 08 (Dentsply Maillefer, Ballaigues, Suíça).Em seguida os dentes permaneceram expostos à cavidade bucal para favorecer a contaminação dos canais radiculares pela microbiota bucal e consequente indução da LP (da Silva et al., 2012).

Os camundongos foram randomizados e eutanasiados em três diferentes períodos: aos 7, 21 e 42 dias em câmaras de $\mathrm{CO}_{2}$, após serem previamente anestesiados. 


\section{Processamento histotécnico}

Após a eutanásia, as mandíbulas inferiores foram removidas, fixadas em formalina tamponada com fosfato a $10 \%$ por $24 \mathrm{~h}$ e, para a descalcificação das peças, foi utilizada uma solução à base de EDTA a 4,13\% (pH 7-7,4), onde a amostra foi mantida por aproximadamente 1 mês. Após isso, as amostras foram submetidas ao processamento histotécnico (Da Silva et al., 2014). Secções semiseriadas longitudinais de $5 \mu \mathrm{m}$ de espessura foram cortadas na direção mesio-distal ao longo da LP.

\section{Imuno-histoquímica}

A imuno-histoquímica foi realizada de acordo com um protocolo previamente publicado (da Silva et al., 2012; Bezerra da Silva et al., 2014). As lâminas foram selecionadas a cada 3 lâminas desde o início da LP até o final da mesma. As lâminas foram incubadas durante a noite com os anticorpos primários (Santa Cruz Biotechnology Inc., Santa Cruz, CA, EUA) diluídos em 1\% de BSA: anti-MMP2 (polyclonal goat K-20 sc8835 Santa Cruz Biotechnology Inc., Santa Cruz, CA, USA, diluído 1:100) e anti-MMP9 (polyclonal goat C-20 sc-6840 Santa Cruz Biotechnology Inc., Santa Cruz, CA, USA, diluído 1:100). Depois de retornarem à temperatura ambiente e todas as etapas de lavagem com PBS e PBS/Triton foram realizadas, logo após as lâminas foram incubadas com um anticorpo secundário biotinilado (goat anti-rabbitIgG-B sc-2040, Santa Cruz Biotechnology Inc., diluídos 1: 200) por 1h à temperatura ambiente. O complexo avidina-biotina-peroxidase (kit ABC, Vecstain, Vector Laboratories Inc.) foi então adicionado durante $30 \mathrm{~min}$. A seguir, as lâminas foram novamente lavadas com PBS e PBS/Triton seguido por lavagem com o cromógeno 3,3 'diaminobenzidina tetrahidrocloreto hidratado (DAB, Sigma-Aldrich Corp., St. Louis, MO, USA), adicionado com peróxido de hidrogênio a $3 \%$ em PBS durante 1 min. As lâminas foram contracoradas com Hematoxilina de Harris. As lâminas de todos os grupos foram analisadas por um examinador calibrado. Os resultados foram expressos como dados semiquantitativos, considerando a intensidade do cromógeno DAB em toda a área da lesão periapical (ausência, leve, moderada ou intensa) para MMP2 e MMP9. Todas as imunomarcações foram analisadas na LP e coincidentemente, a imunomarcação tanto de MMP2 como de MMP9 estavam presentes em toda a extensão da LP independentemente da intensidade de cromógeno DAB. 


\section{Análise Estatística}

A análise estatística foi realizada usando o software Epi-Info 7.0 (Epi Info ${ }^{\mathrm{TM}}$, Atlanta, GA - USA). O teste do qui-quadrado foi utilizado para analisar os resultados semi-quantitativos da imuno-histoquímica. Um nível de significância de 5\% foi utilizado para a análise.

\section{Resultados}

A análise semi-quantitativa dos resultados da imuno-histoquímica mostrou uma diferença estatisticamente significativa na expressão de MMP2 entre os grupos WT, TLR2 KO e MyD88 KO após 42 dias ( $p=0,01)$ (Tabela 1).

Pode-se observar que aos 42 dias, foi observada uma intensidade de coloração menor no grupo de camundongos TLR2 KO (Figura 1).

\begin{tabular}{|c|c|c|c|c|}
\hline Animal & Leve $n(\%)$ & Moderado $n(\%)$ & Severo $n(\%)$ & $p$-valor \\
\hline \multicolumn{5}{|c|}{7 dias } \\
\hline$W T$ & 0 & $3(50,0)$ & $3(50,0)$ & Referência \\
\hline TLR2 KO & $2(33,4)$ & $3(50,0)$ & $1(16,7)$ & 0,22 \\
\hline MyD88 KO & 0 & $3(50,0)$ & $3(50,0)$ & 1,00 \\
\hline \multicolumn{5}{|c|}{21 dias } \\
\hline$W T$ & 0 & $2(33,4)$ & $4(66,7)$ & Referência \\
\hline TLR2 KO & 0 & $4(66,7)$ & $2(33,4)$ & 0,37 \\
\hline MyD88 KO & $1(16,7)$ & $2(33,4)$ & $3(50,0)$ & 0,63 \\
\hline \multicolumn{5}{|c|}{42 dias } \\
\hline$W T$ & 0 & $2(33,4)$ & $4(66,7)$ & Referência \\
\hline TLR2 KO & $4(66,7)$ & $2(33,4)$ & 0 & 0,01 \\
\hline MyD88 KO & 0 & $2(33,4)$ & $4(66,7)$ & 1,00 \\
\hline
\end{tabular}


Figura 1.Fotomicrografias de cortes microscópicos obtidos aos 7, 21 e 42 dias após a indução experimental de lesão periapical em camundongos WT, TLR2 KO and MyD88 KO para a observação da intensidade de marcação a partir da técnica de imunohistoquímica avaliando a MMP2 (40x).



$\mathrm{Na}$ análise da expressão de MMP9, observou-se uma diferença estatisticamente significativa entre os grupos WT, TLR2 KO $(p=0,01)$ e MyD88 KO $(p=0,02)$ aos 7 dias e aos 42 dias observou-se diferença estatisticamente significante somente no grupo TLR2 KO $(p=0,02)$ (Tabela 2$)$.

Tabela 2. Dados semi-quantitativos da imuno-histoquímica referente à marcação de MMP9.

\begin{tabular}{c|c|c|c|c}
\hline Animal & Leve $n(\%)$ & Moderada $n(\%)$ & Severa $n(\%)$ & $p$-valor \\
\hline \multicolumn{5}{c}{7 dias } \\
\hline WT & $5(83,4)$ & $1(16,7)$ & 0 & Referência \\
\hline TLR2 KO & 0 & $5(83,4)$ & $1(16,7)$ & $\mathbf{0 , 0 1}$ \\
\hline MyD88 KO & $1(16,7)$ & $5(83,4)$ & 0 & $\mathbf{0 , 0 2}$ \\
\hline \multicolumn{5}{c}{21 dias } \\
\hline WT & $4(66,7)$ & $2(33,4)$ & 0 & Referência \\
\hline TLR2 KO & $1(16,7)$ & $4(66,7)$ & $1(16,7)$ & 0,17 \\
\hline MyD88 KO & $1(16,7)$ & $4(66,7)$ & $1(16,7)$ & 0,17 \\
\hline \multicolumn{5}{c}{42 dias } \\
\hline WT & $4(66,7)$ & $2(33,4)$ & 0 & Referência \\
\hline TLR2 KO & 0 & $3(50,0)$ & $3(50,0)$ & $\mathbf{0 , 0 2}$ \\
\hline MyD88 KO & $2(66,7)$ & $4(33,4)$ & 0 & 0,24
\end{tabular}

Nota: Teste qui-quadrado foi utilizado. Negrito indica diferença estatística $(p<0.05)$.

Camundongos WT $=6$ animais; TLR2 KO $=6$ animais; MyD88 KO $=6$ animais 
Especificamente aos 7 dias, os camundongos TLR2 KO e MyD88 KO apresentaram uma produção mais intensa de MMP9, enquanto que aos 42 dias, apenas camundongos TLR2 KO mantiveram uma síntese de MMP9 mais elevada (Figura 2).

Figura 2.Fotomicrografias de cortes microscópicos obtidos aos 7, 21 e 42 dias após a indução experimental de lesão periapical em camundongos WT, TLR2 KO and MyD88 KO para a observação da intensidade de marcação a partir da técnica de imunohistoquímica avaliando a MMP9 (40x).
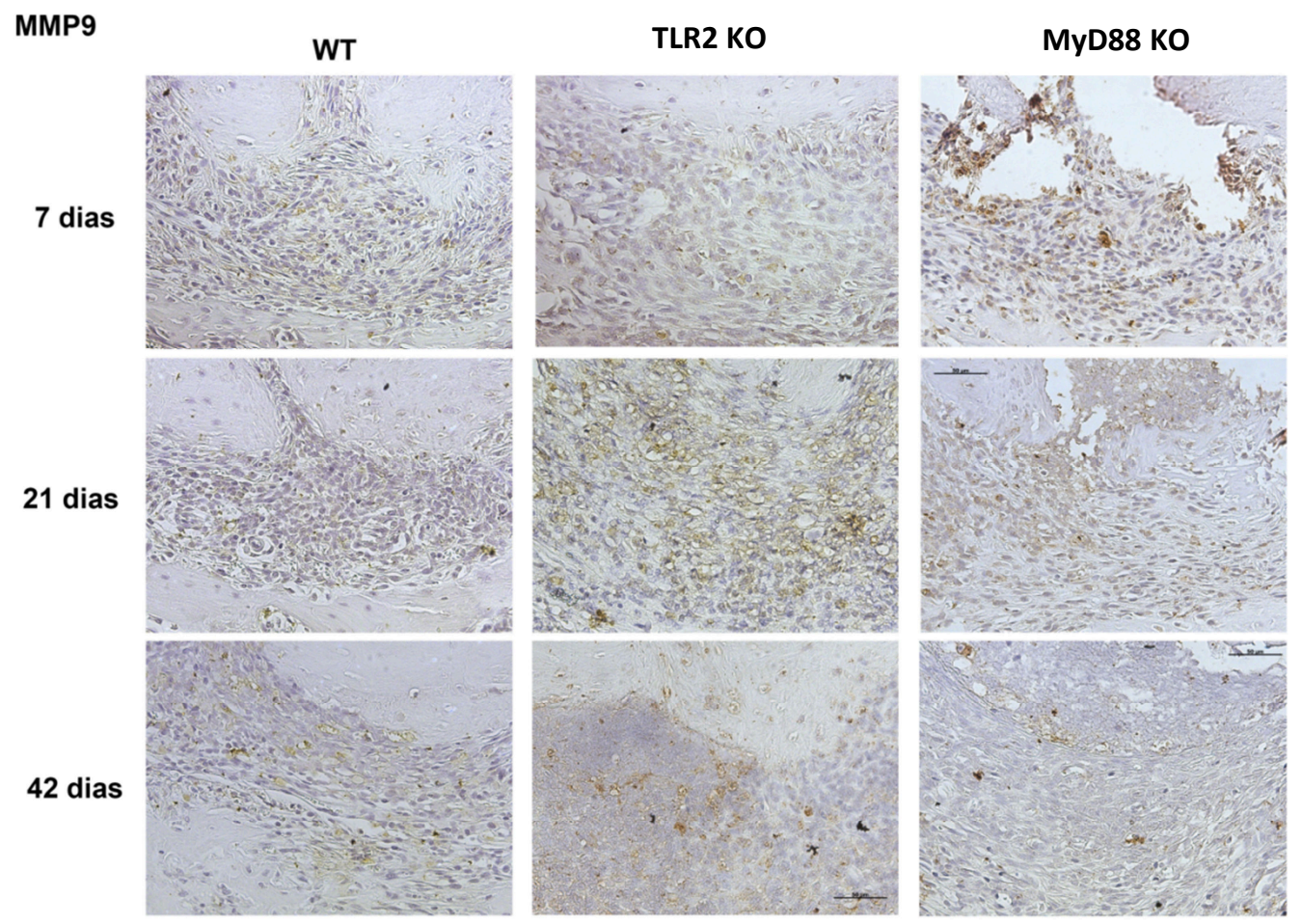

Nos períodos iniciais da progressão da LP foi observado um aumento da expressão de MMP9 nos camundongos TLR2 KO e MyD88 KO. Nos períodos finais de progressão da LP, observou-se uma redução da expressão de MMP2 e um aumento da expressão de MMP9 nos camundongos TLR2 KO.

\section{Discussão}

No presente estudo, camundongos knockout para TLR2 e MyD88 foram utilizados como um modelo experimental. A ausênciade TLR2 e MyD88 permitiu compreender a interação entre MMP2 e MMP9 com estas proteínas fornecendo um conhecimento mais aprofundado sobre a progressão da LP.

Estudos anteriores realizados em camundongos (Kawashima et al., 2007) e humanos (Menezes et al., 2008) sugeriram que MMP2 e MMP9 poderiam estar agindo na degradação da ECM, favorecendo a progressão da lesão e, juntamente com outras citocinas, contribuindo para a destruição óssea na LP. A MMP2 modula 
muitas condições fisiológicas, incluindo reparação de feridas e remodelação de tecidos (Godefroy et al., 2014). Em condições fisiológicas, a MMP2 é expressa por células do ligamento periodontal (Chang et al., 2002) e age em resposta à infecção, a lesão e remodelação tecidual. Em nosso estudo, observamos que a expressão de MMP2 foi menor nos camundongos TLR2 KO do que nos camundongos WT aos 42 dias. Um estudo prévio em células-tronco de glioma também demonstrou que TLR2 regula a expressão de MMP2 (Wang et al., 2015).

A MMP9 é predominantemente produzida por monócitos/macrófagos (Devereux et al., 2014) que estão presentes abundantemente em sítios de inflamação crônica, como a doença periodontal, na qual a degradação do tecido conjuntivo pela MMP9 é considerada como acionadora da patologia da doença (Goetzl et al., 1996). A MMP9 é também essencial para iniciar o processo de reabsorção osteoclástica através da remoção da camada colagenosa da superfície óssea antes do início da desmineralização (Delaissé et al., 2000). Uma interação entre TLR2 e MyD88 com MMP9 também foi demonstrada em células monocíticas (Ahmad et al., 2014). Em nosso estudo, observou-se que a expressão de MMP9 em ambos os camundongos KO foi diferente dos camundongos WT. A expressão de MMP9 em ambos os camundongos KO foi superior aos camundongos WT, podendo assim hipotetizar que TLR2 e MyD88 apresentam um papel protetor na LP, uma vez que na sua ausência a expressão de MMPg foi aumentada durante a progressão da LP.

É importante ressaltar que alguns estudos anteriores demonstraram que TLR2 está envolvido na resposta a uma variedade de componentes bacterianos (Takeuchi et al., 2000). A infecção bacteriana é uma condição para o desenvolvimento de lesões periapicais quando esta é derivada de lesões extensas de cárie. Contudo, a produção de MMP9 foi aumentada em células da polpa humana e do ligamento periodontal estimuladas por patógenos endodônticos (Chang et al., 2002).

Embora muitos estudos tenham avaliado uma grande variedade de moléculas no contexto da LP, o papel de TLR2, MyD88, MMP2 e MMP9 sobre a disseminação da infecção, necrose pulpar e progressão da LP não é completamente entendida. Portanto, estudos adicionais devem ser realizados em animais e humanos para entender melhor a associação entre bactérias, MMPs e sistema imune inato. 


\section{Conclusão}

A produção de MMP2 e MMP9 foi modulada por TLR2 e MyD88 durante a progressão da lesão periapical. 



\section{Capítulo 2}

Expressão de $\mathcal{R} \mathcal{A} \mathcal{N} \mathcal{K}, \mathcal{R} \mathcal{A} \mathcal{N} \mathcal{K} \mathcal{L}, O \mathcal{P} G, \mathcal{T} \mathcal{L} 2$ e $\mathcal{M} y \mathcal{D} 88$ durante a progressão da lesão periapical 



\section{Introdução}

A lesão periapical (LP) representa uma resposta imunoinflamatória do hospedeiro contra a infecção do canal radicular, o que resulta na destruição do ligamento periodontal, do cemento e do osso alveiolar ao redor do ápice da raiz (Kakehashi et al., 1965; Kabak et al., 2005; Lin et al., 2007). Na LP, o processo inflamatório resulta na reabsorção óssea periapical como resultado da atividade dos osteoclastos (Teitelbaum, 2000). O Ligante do Receptor Ativador do Fator Nuclear kappa-B (RANKL), seu receptor RANK, e a osteoprotegerina (OPG) desempenham papéis cruciais na regulação da diferenciação e ativação dos osteoclastos no processo fisiológico e patológico (Haynes et al., 2001; Kawai et al., 2006). O RANKL induz a reabsorção óssea, no entanto, a OPG protege essa destruição, impedindo a ligação RANK/RANKL (Hofbauer and Heufelder, 2001; Geng et al., 2011).

A destruição óssea na progressão da LP, que é causada principalmente pela infecção bacteriana através dos canais radiculares, ocorre como resultado da reação de defesa do hospedeiro. A reação de defesa do hospedeiro durante a LP é composta de várias células inflamatórias, como neutrófilos, macrófagos e linfócitos (Stashenko et al., 1992; Okiji et al., 1994; Kawashima e Stashenko, 1999; Kaneko et al., 2001; Suzuki et al., 2002), que sintetizam mediadores bioquímicos.

Os receptores Toll-like ( $T L R S$ ) são receptores transmembrana tipo 1 que são fortemente expressos em vários tipos de células associados a infecções de origem endodôntica, tais como neutrófilos, monócitos/macrófagos (Hayashi et al., 2003, Nilsen et al., 2004) granulócitos e fibroblastos localizados na polpa, precursores de osteoclastos e células mesenquimais (Hirao et al., 2009; Bar-Shavit, 2008). Os TLRS exercem um papel importante no reconhecimento de componentes específicos derivados de patógenos (Takeda e Akira, 2005) e transmitindo sinais apropriados para as células do sistema imunológico (Medzhitov et al., 1997).

O reconhecimento dos micro-organismospelos $T L R S$, seus componentes e produtos estimulam a produção de citocinas pró-inflamatórias e moléculas coestimuladoras, responsáveis pelas diferentes respostas obtidas durante a identificação ocorrida pelos padrões moleculares associados a patógenos (Takeda e Akira, 2005). A ativação dos TLRS é o passo inicial da ativação em cascata no recrutamento de diferentes moléculas adaptadoras (Janssens e Beyaert, 2002). Uma dessas moléculas é 
o fator de diferenciação mielóide 88 (MyD88). O papel da MyD88 como uma molécula adaptadora universal, foi comprovado durante a indução da produção de citocinas próinflamatórias, por estimulação com vários ligantes, que ativaram diferentes receptores transmembranas, uma vez que todos tinham em comum a exigência do recrutamento da MyD88 (Adachi et al., 1998; Schnare et al., 2000, Alexpoulou et al., 2001).

Muitas citocinas pró-inflamatórias estão associadas com a regulação na formação dos osteoclastos, osteoclastogênese e reabsorção óssea (Hirao et al., 2009; Bar-Shavit, 2008). A ativação dos TLRS, por ligantes microbianos, desencadeia vias de sinalizações específicas intracelulares que conduzem a uma liberação maior de mediadores inflamatórios, incluindo a expressão de proteínas RANK/RANKL/OPG e mediadores da homeostase de tecidos mineralizados (Aderem and Ulevitch, 2000; Hou et al., 2000). Além disso, a MyD88 está envolvida na regulação de RANKL e na expressão de OPG induzida pela via de sinalização TLR2 e TLR4 (Leite et al., 2015). Portanto, este estudo teve como objetivo avaliar a correlação da expressão gênica e imunomarcação de RANK, RANKL, OPG, TLR2 e MyD88 durante a progressão da LP em camundongos.

\section{Material e Métodos}

\section{Animais}

Todos os procedimentos com os animais foram realizados de acordo com as diretrizes éticas aplicáveis e os regulamentos do Comitê de Ética no Uso de Animais da Universidade de São Paulo - Campus de Ribeirão Preto após a aprovação do projeto de pesquisa(Número do processo: 2014.1.911.58, Anexo B). Foram utilizados 35 camundongos da linhagem C57BL/6, machos, com 6 a 8 semanas de idade e $20 \mathrm{~g}$ de peso. Os camundongos foram obtidos do Biotério Central da Universidade de São Paulo, Campus de Ribeirão Preto, Brasil.

\section{Indução da $L P$}

As LP foram induzidas em ambos os primeiros molares inferiores (esquerda e direita) dos camundongos. Foi realizado anestesia intramuscular nos animais com Ketamina 10\% (150 mg/kg de peso - Agener União Química Farmacêutica Nacional 
S/A, Embu-Guaçu, SP) e Xilazina 2\% (7,5 mg/kg de peso, Dopaser, Laboratórios Calier SA, Barcelona, Espanha). Em seguida, os animais foram colocados em uma mesa cirúrgica específica para visualização adequada e fácil acesso aos molares inferiores.

A indução de LP foi baseada em protocolo previamente publicado (De Rossi et al., 2008; da Silva et al., 2012). Os primeiros molares mandibulares inferiores foram expostos à cavidade bucal, com uma broca de aço inoxidável esférica de tamanho 1/4 (GDK Densell Dental Technology, Buenos Aires, Argentina) acoplada a uma peça de mão de baixa rotação para acessar a câmara pulpar. Após isso, foram utilizadas limas tipo K endodônticas de tamanho 8 (Maillefer S/A, Suíça) para a localização dos canais radiculares e contaminação pela microbiota bucal do animal.

Os animais foram eutanasiados com injeção intramuscular com Ketamina e Xilazina e submetidos a inalação de $\mathrm{CO}_{2}$ em uma câmara específica após os períodos de 0, 7, 21 e 42 dias (Tabela 1).

Após a eutanásia, as mandíbulas foram removidas com tesouras cirúrgicas estéreis e se obteve duas hemi-arcadas. A mandíbula direita foi submetida ao processamento histotécnico, enquanto que a esquerda foi imersa em RNA later solution $^{\circledR}$ (Ambion $^{\mathrm{TM}}$, Carlsbad, CA, EUA) para avaliação da expressão gênica por meio da técnica de qRT-PCR.

Tabela 1: Descrição dos grupos animais.

\begin{tabular}{c|c|c}
\hline Grupos & Períodos (dias) & n (animais) \\
\hline G0 & 0 & 5 \\
\hline G7 & 7 & 10 \\
\hline G21 & 21 & 10 \\
\hline G42 & 42 & 10 \\
\hline
\end{tabular}

\section{Processamento histotécnico}

As mandíbulas do lado direito foram removidas, fixadas em formalina tamponada com fosfato a 10\% durante 24 h em temperatura ambiente. Após isso, as peças foram lavadas em água corrente por 4 horas e desmineralizadas em ácido etilenodiaminotetracético a 4,13\% $(\mathrm{pH} 7.2)$ em temperatura ambiente, trocado a cada semana até completar 30 dias. Uma vez descalcificados, os espécimes foram 
novamente lavados em água corrente por 2 horas, desidratado em diluições ascendentes de etanol, diafanizados em xilol e incorporados a parafina. Secções semi-seriadas de $5 \mu \mathrm{m}$ de espessura foram cortadas longitudinalmente seguindo a orientação de direção mesio-distal ao longo da LP.

\section{Imuno-histoquímica}

A imunomarcação foi realizada nos grupos G7, G21 e G42 e realizada de acordo com protocolos previamente publicados (da Silva et al., 2012; Bezerra da Silva et al., 2014). As lâminas foram incubadas durante a noite com os anticorpos primários diluídos em 1\% de BSA (albumina de soro bovino): anti-RANK (diluído 1:100; Santa Cruz Biotechnology Inc., Dallas, TX, EUA), anti-RANKL (diluído 1:100; Santa Cruz Biotechnology Inc.), anti-OPG (diluído 1:100; Santa Cruz Biotechnology Inc.), anti-TLR2 (diluído 1:100; Santa Cruz Biotechnology Inc.) e anti-MyD88 (diluído 1:50; Santa Cruz Biotechnology Inc.). Depois de voltar à temperatura ambiente e realizar as lavagens, as lâminas foram incubadas com o anticorpo secundário biotinilado (goat anti-rabbit IgG-B e rabbit anti-goat IgG-B, diluído 1:200; Santa Cruz Biotechnology Inc.) por 1 hora em temperatura ambiente. 0 complexo avidinabiotina-peroxidase (kit ABC, Vecstain, Vector Laboratories Inc.) foi adicionado por 30 min, seguido por lavagem com o cromógeno 3,3 'diaminobenzidina tetrahidrocloreto hidratado (DAB, Sigma-Aldrich Corp., St. Louis, MO, EUA), adicionado com peróxido de hidrogênio a 3\% em PBS durante 1 min. As lâminas foram contra coradas com Hematoxilina de Harris. Os resultados foram expressos como a presença ou ausência de RANK, RANKL, OPG, TLR2 e MyD88 para cada espécime.

\section{qRT-PCR}

Ahemi mandíbula do lado esquerdo foram submetidas a um kit específico para extração de ácido nucleico (extração total de RNA) (PureLink RNA Mini Kit, Ambion, Life Technologies, Carlsbad, CA, EUA). Os procedimentos foram realizados de acordo com o protocolo do fabricante. A quantidade de RNA extraído foi estimado utilizando um espectrofotômetro (Thermo Fisher Scientific Inc, Wilmington, DE) com um comprimento de onda de $260 \mathrm{~nm}$. Posteriormente, o RNA extraído foi convertido em cDNA com o uso de um kit comercial (High Capacity cDNA Reverse Transcription Kit, 
Applied Biosystems, Lituânia). Resumidamente, os genes de RANK, RANKL, OPG, TLR2 e MyD88avaliados estão descritos na Tabela 2. Gapdh e Actb foram utilizados como genes de referência. As reações de qRT-PCR foram realizadas em duplicata utilizando TaqMan Gene Expression Assay (Applied Biosystems, Foster City, Califórnia, EUA). A quantificação relativa foi realizada utilizando o método 2- $\Delta \Delta \mathrm{Ct}$.

Tabela 2. Descrição dos genes estudados

\begin{tabular}{l|l|l|l}
\hline Função do gene & Símbolo & $\begin{array}{l}\text { Nome do } \\
\text { gene }\end{array}$ & Assay ID \\
\hline \multirow{2}{*}{$\begin{array}{l}\text { Modelação e remodelação } \\
\text { óssea }\end{array}$} & RANK & Tnfrsf11a & Mm 00437135_m1 \\
\cline { 2 - 4 } & RANKL & Tnfrsf11 & Mm 00441906_m1 \\
\cline { 2 - 4 } & OPG & Tnfrsf11b & Mm 01205928_m1 \\
\hline \multirow{2}{*}{ Sistema imune inato } & TLR2 & TIr2 & Mm 00442346_m1 \\
\cline { 2 - 4 } & MyD88 & Myd88 & Mm 00440338_m1 \\
\hline
\end{tabular}

\section{Análise Estatística}

Para a imuno-histoquímica foi utilizado o teste qui-quadrado para analisar a presença e ausência de acordo com os grupos. Os dados da expressão gênica foram avaliados de acordo com os grupos utilizando o teste oneway ANOVA, seguido pelo teste de Tukey. A razão RANKL/OPG também foi calculada apenas para a expressão do mRNA.

O teste de coeficiente de Spearman foi utilizado para avaliar o grau de correlação entre a expressão de genes. A intensidade das correlações positivas e negativas foi definida de acordo com o valor do "Coeficiente de Correlação" ( $r$ ) (1: perfeito; 0,7 a 0,9: forte; 0,4 a 0,6: moderado; 0,1 a 0,3: fraco; 0: sem correlação).

Todas as análises foram realizadas utilizando o Graph Pad Prism 5.0 (Graph Pad Software Inc., San Diego, CA, EUA). O nível de significância adotado para todas as análises foi de $5 \%$ 


\section{Resultados}

\section{Imuno-histoquímica}

Figura 1 demonstra a presença versus a ausência de imuno-marcação positiva para RANK (A), RANKL (B), OPG (C), TLR2 (D) and MyD88 (E) aos 7, 21 e 42 dias. Foi possível observar um aumento na imunomarcação de RANK, RANKL, OPG, TLR2 and MyD88 $(p<0,05)$ durante a progressão da LP (Figura 2).

Figura 1. Representação gráfica da distribuição de imunomarcação (presença ou ausência) de RANK (A), RANKL (B), OPG (C), TLR2 (D) e MyD88 (E) nos camundongos wild type após indução da lesão periapical nos períodos de 7, 21 e 42 dias.

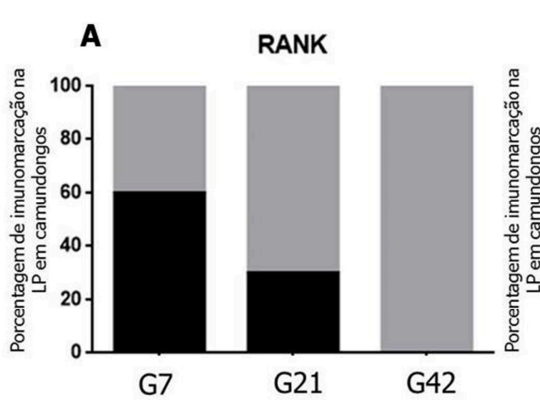

B

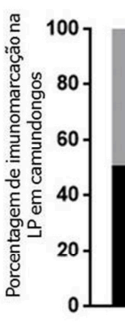

RANKL

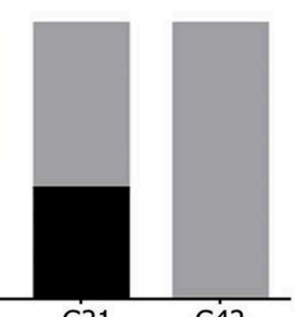

C

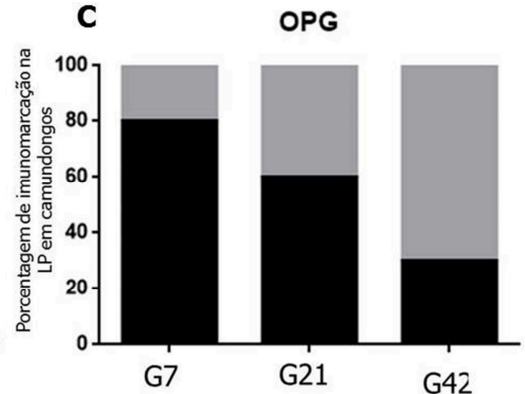

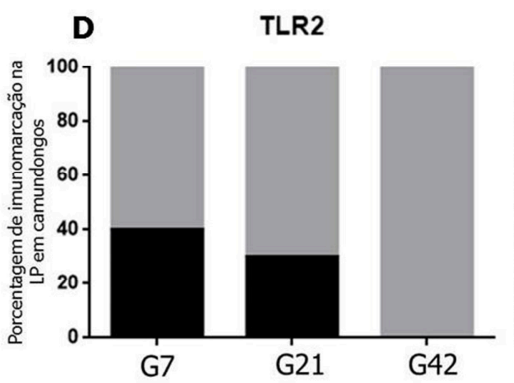

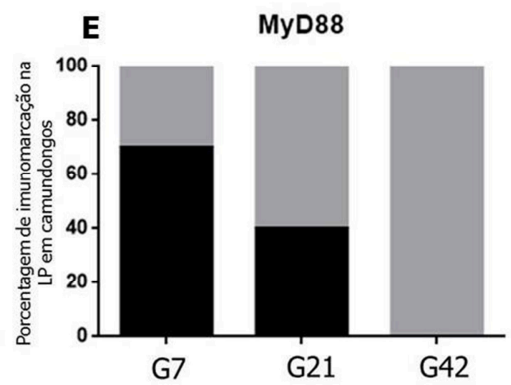

Presente

Ausente

G7

$$
42
$$


Figura 2. Fotomicrografias de cortes microscópicos obtidos aos 7, 21 e 42 dias após a indução experimental de lesão periapical em camundongos wild type a observação da presença ou ausência de marcação a partir da técnica de imuno-histoquímica avaliando a RANK, RANKL, OPG, TLR2 e MyD88 (20x).

\section{RANK}

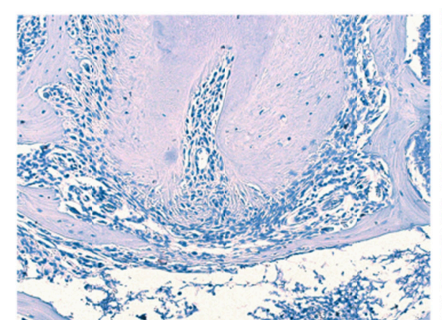

G7
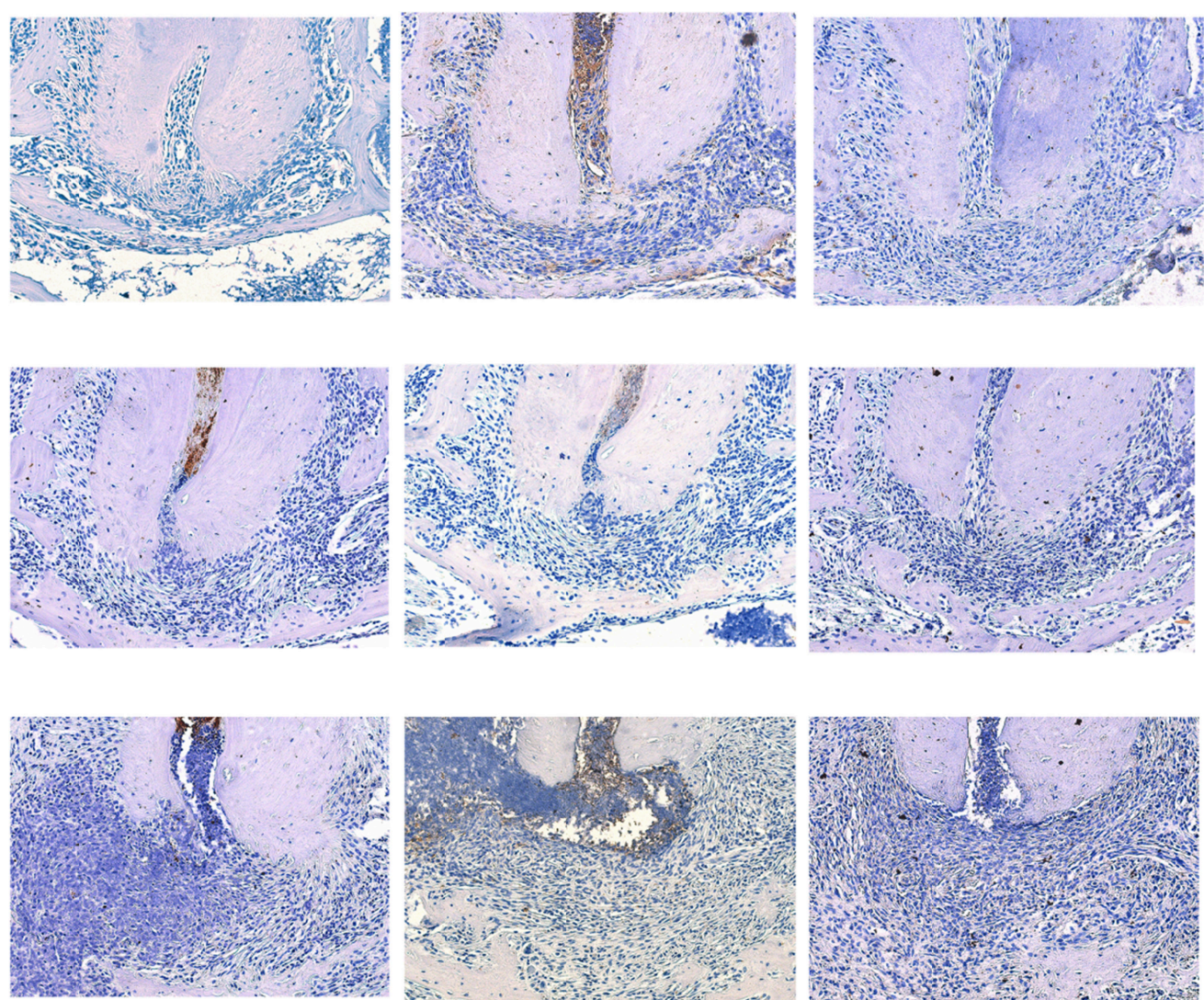
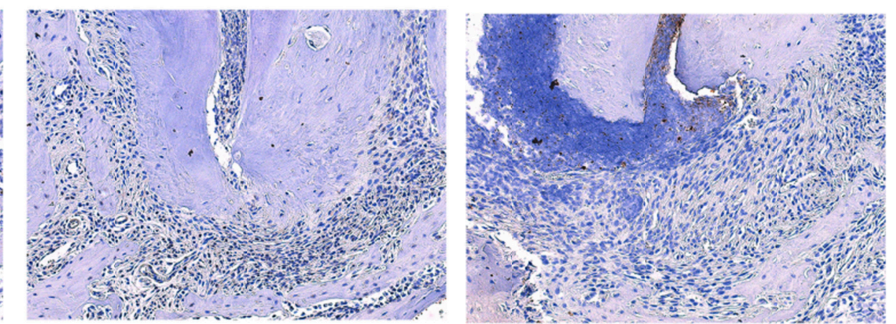

TLR2

MyD88
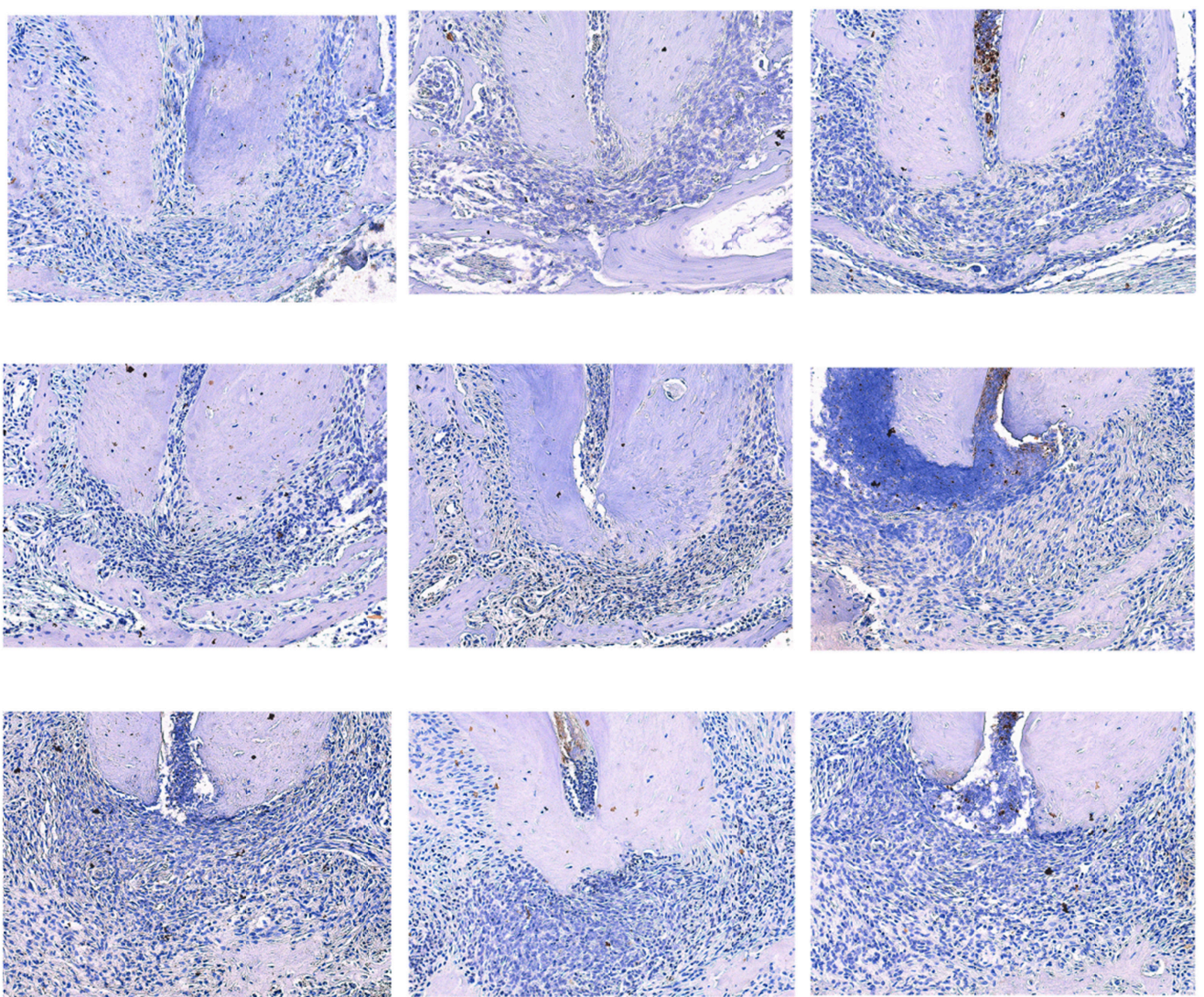


\section{Expressão gênica}

A expressão de RANK não foi alterada ao longodo tempo $(p=0,114)$ (Figura 3A). No entanto, a expressão de RANKL foi estatisticamente diferente entre os grupos G0 e G42 eentre os grupos G21 e G42 $(p=0,006)$ (Figura 3B). A expressão gênica da OPG foi estatisticamente significante maior entre os grupos $G 0$ e $G 7$, além da diferença entre G7 e G21, G7 e G42 ( $p<0,001)$ (Figura 3C).

Analisando os genes do sistema imune inato, a expressão de TLR2 foi estatisticamente diferente maior entre os grupos G0 e G42( $p=0,03)$ (Figura 3D). Já a expressão de MyD88 foi estatisticamente maior entre os grupos G0 e G7, G21 e G42 $(p=0,01)$ (Figura 3E).

Figura 3. Representação gráfica da distribuição da expressão de mRNA. Tnfrsf11a (A), Tnfrsf11 (B), Tnfrsf11b (C), TIr2 (D) e Myd88 (E) em camundongos após indução de LP nos períodos de 0, 7, 21 e 42 dias. 0 asterisco demonstra diferença estatística $(\mathrm{p}<0,05)$.
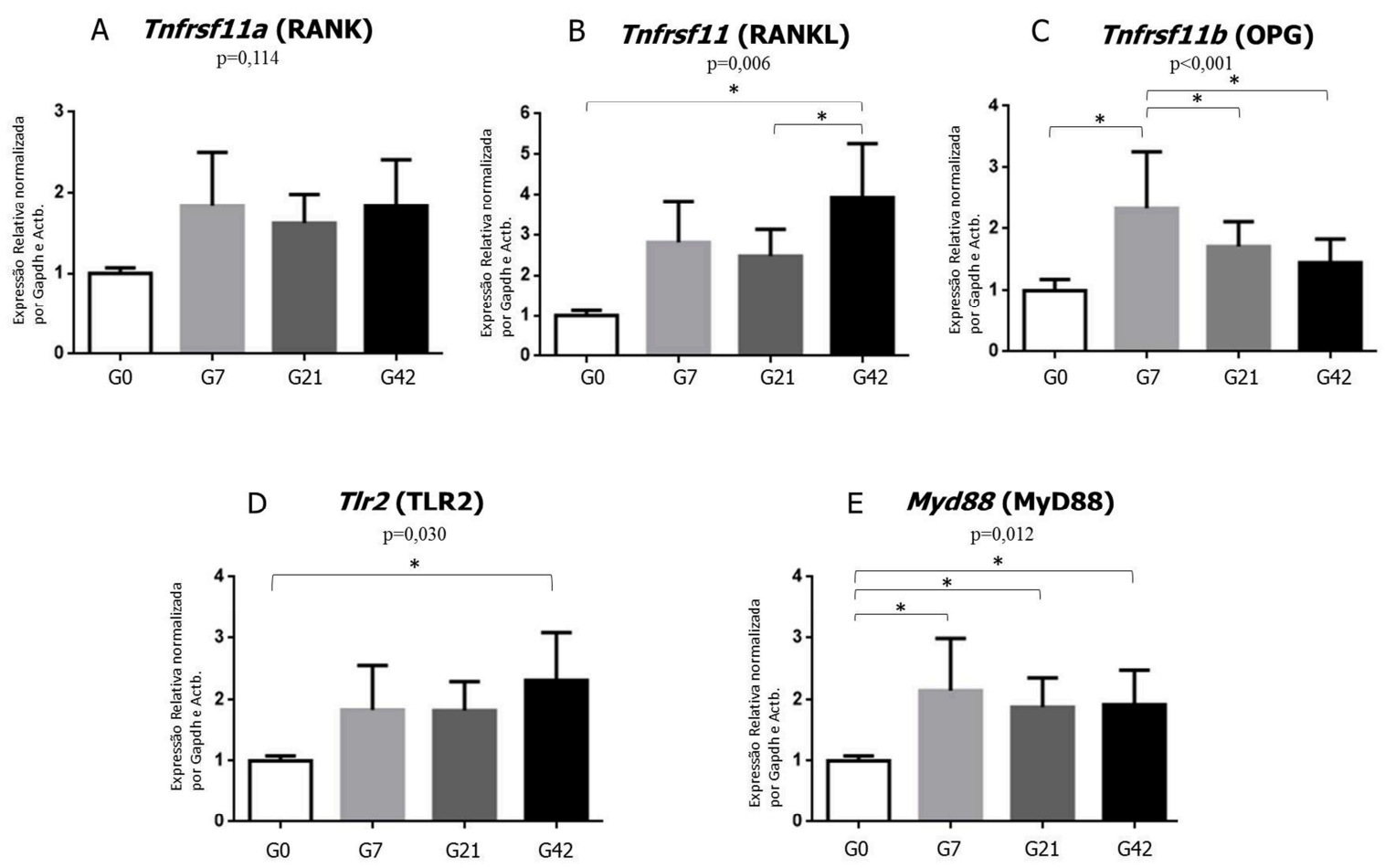


\section{Razão entre RANKL/OPG}

Figura 4 demonstra a razão RANKL/OPG de acordo com os períodos analisados. Foi possível observar que a proporção de RANKL para OPG aumentou progressivamente com a LP $(p=0,002)$.

Figura 4. Representação gráfica da relação Tnfrsf11/Tnfrsf11b durante a progressão da LP. $O$ asterisco demonstra diferença estatística $(p<0,05)$.

\section{Razão de Tnfrsf11/Tnfrsf11b} (RANKL/OPG)

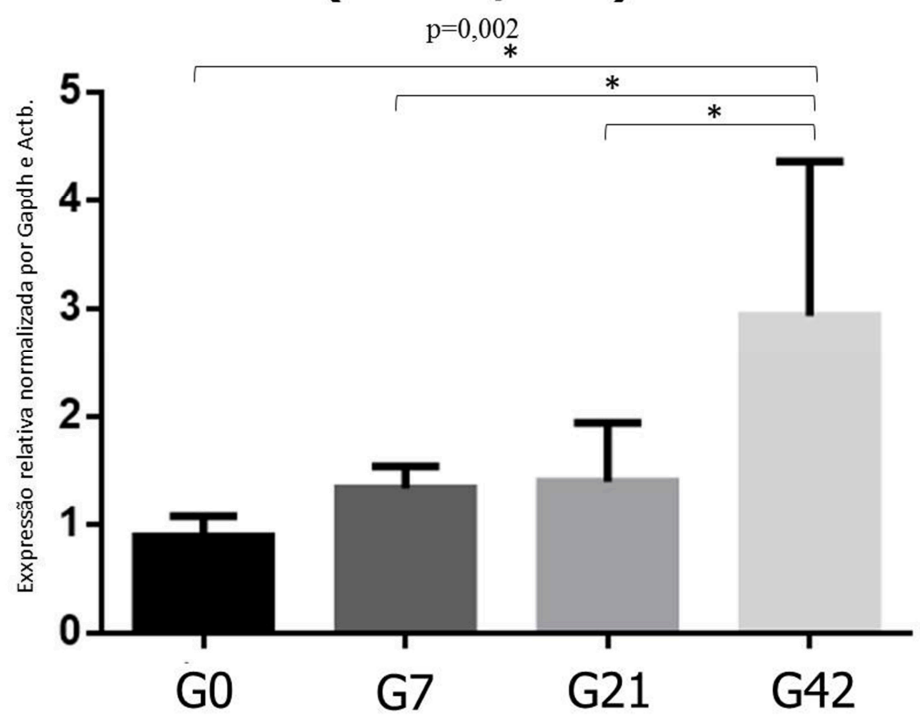

\section{Teste de Correlação}

No teste de correlação de Spearman foi possível observar que existe uma correlação moderada entre a molécula adaptados MyD88 e o RANKL $(r=0,42$; $p=0,03)$. Também foi possível observar uma correlação moderada entre MyD88 e TLR2 ( $r=0,48 ; p<0,0001$ ) (Tabela 3).

Tabela 3: Correlação entre as expressões dos mRNAs.

\begin{tabular}{c|c|c}
\hline & TIr2 & Myd88 \\
\hline Tnfrsf11a & $\mathrm{r}=0,12$ & $\mathrm{r}=0,14$ \\
& $\mathrm{p}=0,53$ & $\mathrm{p}=0,47$ \\
\hline Tnfrsf11 & $\mathrm{r}=0,27$ & $\mathrm{r}=0,42$ \\
& $\mathrm{p}=0,17$ & $\mathrm{p}=\mathbf{0 , 0 3}$ \\
\hline Tnfrsf11b & $\mathrm{r}=-0,09$ & $\mathrm{r}=0,22$ \\
& $\mathrm{p}=0,64$ & $\mathrm{p}=0,26$ \\
\hline Myd88 & $\mathrm{r}=0,51$ & - \\
& $\mathbf{p}<\mathbf{0 , 0 0 0 1}$ & \\
\hline
\end{tabular}

Nota: Marcações em negrito indicam diferença estatística $(p<0.05)$ 


\section{Discussão}

Nas duas últimas décadas, houve um aumento na pesquisa no campo da biologia óssea. Um evento notável foi à identificação e caracterização do sistema RANK/RANKL/OPG (Khosla, 2001) e seu papel no metabolismo ósseo. Diversas evidências tem destacado a importância dessas moléculas na fisiopatologia dos processos de origem endodôntica (Kawashima et al., 2007, Menezes et al., 2008, da Silva et al, 2012, Belibasakis et al., 2012, Bezerra da Silva et al. 2014, Rechenberg et al., 2014, Armada et al., 2015, Estrela et al., 2016, Carneiro et al., 2017). Outro avanço importante na pesquisa endodôntica foi a identificação de receptores e moléculas adaptadoras envolvidas no sistema imune inato durante a progressão da LP (Desai et al., 2011, da Silva et al., 2012, Bezerra da Silva et al., 2014, Özan et al. 2016, Rider et al., 2016). TLR2 e MyD88 têm um papel importante no reconhecimento de patógenos e na ativação da do sistema imune inato (Medzhitov et al., 1997, Adachi et al., 1998, Schnare et al., 2000, Alexpoulou et al., 2001, Takeda e Akira, 2005).

Em 2012, nosso grupo de pesquisa caracterizou a formação e a progressão da lesão periapical induzida experimentalmente em molares de camundongos knockout para TLR2, concluindo que estes animais desenvolveram maior lesão periapical com maior número de osteoclastos, indicando o papel deste receptor na resposta imune e inflamatória do hospedeiro em resposta à infecção perirradicular (da Silva et al., 2012). Após disso, utilizando camundongos knockout para MyD88, analisamos a progressão da LP durante 7, 21 e 42 dias. Conclui-se que os camundongos knockout para MyD88 desenvolveram lesões periapicais maiores quando comparados aos camundongos wild type. Além disso, observou-se maior quantidade de osteoclastos na LP e o sistema RANK/RANKL/OPG, analisado por imuno-histoquímica, foi detectado em todos os períodos experimentais (Bezerra da Silva et al., 2014).

No presente estudo, a razão RANKL/OPG aumentou de acordo com a progressão LP. O equilíbrio entre a expressão de RANKL e de OPG é essencial para determinar a resposta biológica na doença periodontal (Garlet et al., 2006, Jin et al., 2007), no movimento dentário ortodôntico (Dunn et al., 2007; Garlet et al. 2007), em algumas lesões osteolíticas no esqueleto facial (Tay et al., 2004) e na lesão periapical (Menezes et al., 2008, Belibasakis et al., 2013, Armada et al., 2015). Menezes et al.(2008) sugeriram que sítios com reabsorção óssea ativa apresentam 
um padrão diferencial de expressão de RANKL/OPG quando comparados com locais onde a reabsorção óssea estava ausente ou foi mínima. Comparando esses padrões característicos da expressão de RANKL/OPG com aqueles vistos em lesões periapicais, os autores puderam sugerir que amostras onde a expressão de RANKL predominou há a presença de lesões progressivas putativas, enquanto amostras onde a expressão de RANKL e OPG é similar ou onde OPG é prevalente as lesões foram potencialmente estáveis. Num determinado momento durante 0 desenvolvimento da lesão, o equilíbrio de RANKL e OPG e a redução da ativação dos osteoclastos tende a ocorrer, resultando em uma lesão periapical crônica.

Nossos resultados demonstraram também que TLR2 apresentou uma maior expressão gênica aos 42 dias. Na literatura, estudos demonstraram que o TLR2 é crucial para a perda óssea inflamatória em resposta à infecção bacteriana, por exemplo, na doença periodontal inflamatória crônica (Ukai et al., 2008). TLR2 também participa da transdução de sinal ativada pelo LPS bacteriano de alguns agentes patogênicos tais como Porphyromonas gingivalis (Yamagishi et al., 2011) e Porphyromonas endodontalis (Tang et al., 2011) por meio da ligação com a molécula auxiliar MD-2 que se expressa em leucócitos e diferentes células inflamatórias, participando na resposta imune (Dziarski et al., 2000). A lesão periapical é causada por uma infecção bacteriana que ocorre na polpa dentária e que leva ao desenvolvimento de uma lesão decorrente da reabsorção óssea patogênica (Stashenko et al., 1998; Marton e Kiss, 2000) e alguns estudos que avaliaram a progressão da LP demonstraram que aos 42 dias os animais desenvolveram extensas LP (da Silva et al., 2012, Bezerra da Silva et al., 2014). Portanto, a alta expressão de TLR2 aos 42 dias pode ser explicada devido à presença de bactérias nas quais estavam envolvidas na ativação da transdução de sinal. Além disso, in vitro, Ukai et al. (2008) demonstraram que a sinalização de TLR2 induzida por macrófagos estimula a osteoclastogênese após a estimulação bacteriana, por outro lado da Silva et al. (2012) demonstraram que camundongos knockout para TLR2 apresentaram aumento da LP e maior número de osteoclastos, sugerindo que TLR2 interage com o sistema RANK/RANKL/OPG durante a progressão da LP.

Contudo, descrevemos neste estudo que a expressão de TLR2 não esteve correlacionada com RANK, RANKL e OPG. Embora uma correlação moderada 
foiobservada entre RANKL e MyD88. A sinalização mediada por MyD88 é essencial para a osteoclastogênese e está fisiologicamente envolvido na renovação óssea. Os sinais mediados por MyD88 induziram a expressão de RANKL em osteoblastos e auxiliaram na sobrevivência dos osteoclastos induzidos por LPS (Sato et al., 2004). A histomorfometria óssea revelou que os camundongos knockout para MyD88 exibiram osteopenia típica com redução na formação e reabsorção óssea (Sato et al., 2004). E com base na análise imuno-histoquímica,Bezerra da Silva et al. (2014) relataram níveis semelhantes de imunomarcação para RANK, RANKL e OPG em camundongos knockoutpara MyD88 e WT aos 7, 21 e 42 dias (Bezerra da Silva et al., 2014).

A molécula adaptadora MyD88 é induzida pelos ligantes dos TLRs (Sato et al., 2004). Nossos resultados demonstraram uma correlação moderada entre TLR2 e MyD88. Estudos anteriores mostraram que o aumento da expressão de MyD88 provoca uma forte ativação de RANKL e sua ausência reduz essa ativação (Medzhitov et al., 1998; Burns et al., 1998). Um estudo recente demonstrou que a MyD88 está envolvida na inibição da expressão de OPG induzida por LPS (Leite et al., 2015). A expressão de RANKL demonstrou ser induzida por osteoblastos estimulados com LPS através da ativação de MyD88 (Yang et al., 2005). E as expressões de RANKL induzidas por citocinas inflamatórias e LPS são extremamente dependentes de MyD88 (Sato et al., 2004).

\section{Conclusão}

Podemos concluir que a expressão de RANK, RANKL, OPG, MyD88 e TRL2 esteve aumentada com a progressão da LP. A análise de mRNA mostrou um aumento na razão Tnfrsf11/Tnfrsf11b (RANKL/OPG) ao longo do tempo e uma correlação positiva entre a expressão de Myd88-Tnfrsf11(MyD88-RANKL) e T/r2Myd88(TLR2-MyD88), suportando a relevância de TLR2-MyD88 na perda óssea decorrente da infecção bacteriana. 
Conclusão 

O presente estudo caracterizou-se pela avaliação de moléculas do sistema imune inato, juntamente com metaloproteinases e o sistema RANK, RANKL, OPG, durante o desenvolvimento das lesões periapicais tanto em camundongos wild type quanto em camundongos knockout para TLR2 e MyD88.

Foi possível concluir que TLR2 e MyD88 modulam a produção de MMP2 e MMP9 durante a progressão da lesão periapical. Além disso, podemos concluir qua a expressão de RANK, RANKL, OPG, TLR2 e MyD88 aumentaram durante a progressão da lesão periapical, demonstrando uma associação positiva entre moléculas do sistema imune inato e o sistema RANK, RANKL e OPG. Também foi possível concluir que na análise da expressão da razão de Tnfrsf11/Tnfrsf11b (RANKL/OPG) durante a progressão da $L P$, realizada por $q R T-P C R$, aumentou ao longo do tempo e uma correlação positiva entre a expressão de Myd88-Tnfrsf11(MyD88-RANKL) e TIr2Myd88(TLR2-MyD88), suportando a relevância de TLR2-MyD88 na perda óssea induida pela infecção bacteriana. 

Referências 

Accorsi-Mendonca T, Silva EJ, Marcaccini AM, Gerlach RF, Duarte KM, Pardo AP, et al. Evaluation of gelatinases, tissue inhibitor of matrix metalloproteinase-2, and myeloperoxidase protein in healthy and inflamed human dental pulp tissue. J Endod. 2013 Jul;39 (7):879-82.

Adachi O, Kawai T, Takeda K, Matsumoto M, Tsutsui H, Sakagami M, et al. Targeted disruption of the MyD88 gene results in loss of IL-1- and IL-18-mediated function. Immunity. 1998;9(1):143-50.

Aderem A, Ulevitch $\mathrm{RJ}$. Toll-like receptors in the induction of the innate immune response. Nature 2000; 406, 782-7.

Ahmad R,Shihab PK,Jasem S, Behbehani K. FSL-1induces MMP-9 production through TLR-2and NF-KB/AP-1 signaling pathways in monocytic THP-1 cells. Cell Physiol Biochem. 2014;34(3):929-42.

Alberts B. Junções celulares, adesão cellular e a matri extracellular. In: Alberts B. Biologia molecular da célula. Porto Alegre: Artes médicas, 1997, p948-1009.

Alexopoulou L, Holt AC, Medzhitov R, Flavell RA. Recognition of double-stranded RNA and activation of NF-kappaB by Toll-like receptor 3.Nature. 2001 Oct;413(6857):7328.

Aliprantis AO, Yang RB, Mark MR, Suggett S, Devaux B, Radolf JD, , et al. Cell activation and apoptosis by bacterial lipoproteins through toll-like receptor-2. Science. 1999 Jul;285(5428):736-9.

Alliston T, Derynck R. Interfering with bone remodelling. Nature. 2002 Apr;416(6882):686-7.

Andrade WA, Souza Mdo C, Ramos-Martinez E, Nagpal K, Dutra MS, Melo MB, et al. Combined action of nucleic acid-sensing Toll-like receptors and TLR11/TLR12 heterodimers imparts resistance to Toxoplasma gondii in mice. Cell Host Microbe. 2013 Jan $16 ; 13(1): 42-53$.

Armada L,Marotta P dos S,Pires FR,Siqueira JF Jr. Expression and Distribution of Receptor Activator of Nuclear Factor KappaB, Receptor Activator of Nuclear Factor KappaB Ligand, and Osteoprotegerin in Periradicular Cysts. J Endod. 2015 Aug;41(8):1281-7. 
Assed S, Ito IY, Leonardo MR, Silva LAB, Lopatin DE. Anaerobic microorganisms in root canals of human teeth with chronic apical periodontitis detected by indirect immunofluorescence. Endod Dent Traumatol. 1996 Apr;12(2):66-9.

Avbelj M, Horvat S, Jerala R. The role of intermediary domain of MyD88 in cell activation and therapeutic inhibition of TLRs. J Immunol. 2011 Sep;187(5):2394-404.

Babu MM, Priya ML, Selvan AT, Madera M, Gough J, Aravind L, et al. A database of bacterial lipoproteins (DOLOP) with functional assignments to predicted lipoproteins. J Bacteriol. 2006 Apr;188(8):2761-73.

Bai Y, Zhu Z, Gao Z, Kong Y. TLR2 signaling directs NO-dependent MMP-9 induction in mouse microglia. Neurosci Lett. 2014 Jun 13;571:5-10.

Bar-Shavit Z. Taking a toll on the bones: regulation of bone metabolism by innate immune regulators. Autoimmunity. 2008 Apr;41(3):195-203.

Belibasakis GN, Rechenberg DK, Zehnder M. The receptor activator of NF-KB ligandosteoprotegerin system in pulpal and periapical disease. Int Endod J. 2013 Feb;46(2):99-111.

Belmar MJ, Pabst C, Martinez B, Hernández M. Gelatinolytic activity in gingival crevicular fluid from teeth with periapical lesions. Oral Surg Oral Med Oral Pathol Oral Radiol Endod. 2008 Jun;105 (6):801-6.

Benarafa C, Priebe GP, Remold-O'Donnell E. The neutrophil serine protease inhibitor serpinb 1 preserves lung defense functions in Pseudomonas aeruginosa infection. J Exp Med. 2007 Aug 6;204(8):1901-9.

Bezerra da Silva RA, Nelson-Filho P, Lucisano MP, De Rossi A, de Queiroz AM, Bezerra da Silva LA. MyD88 knockout mice develop initial enlarged periapical lesions with increased numbers of neutrophils. Int Endod J. 2014 Jul;47(7):675-86.

Birkedal-Hansen H, Moore WG, Bodden MK, Windsor $\mathrm{U}$, Birkedal-Hansen B, DeCarlo A, et al. Matrix metalloproteinases: a review. Crit Rev Oral Biol Med. 1993;4(2):197250.

Bradley LM, Douglass MF, Chatterjee D, Akira S, Baaten BJ. Matrix metalloprotease 9 mediates neutrophil migration into the airways in response to influenza virus-induced toll-like receptor signaling. PLoS Pathog. 2012;8(4):e1002641. 
Brooks PC, Silletti S, von Schalscha TL, Friedlander M, Cheresh DA.Disruption of angiogenesis by PEX, a noncatalytic metalloproteinase fragment with integrin binding activity.Cell. 1998 Feb 6;92:391-400.

Burgner D, Harnden A. Kawasaki disease: what is the epidemiology telling us about the etiology? Int J Infect Dis. 2005 Jul;9(4):185-94.

Burns E, Brahrach G, Shapira L, Nussbaum G. TLR2 is required for the innate response to Porphyromonas gingivalis: activation leads to bacterial persistence and TLR2 deficiency attenuates induced alveolar bone resorption. J Immunol. 2006 Dec;177(12):8296-300.

Burns K, Martinon F, Esslinger C, Pahl H, Schneider P, Bodmer JL, et al. MyD88, an adapter protein involved in interleukin-1 signaling. Journal of Biological Chemistry. $1998 ; 273(20): 12203-9$.

Buzoglu HD, Unal H, Ulger C, Mert S, Kücükuildirim S, Er N. The zymographic evaluation of gelatinase (MMP- 2 and -9) levels in acute and chronic periapical abscesses. Oral Surg Oral Med Oral Pathol Oral Radiol Endod. 2009 Nov;108(5):e121-6.

Campos K, Franscisconi CF, Okehie V, de Souza LC, Trombone AP, Letra A, et al. FOXP3 DNA methylation levels as a potential biomarker in the development of periapical lesions. J Endod. 2015 Feb;41(2):212-8.

Cao Z, Li C, Jin L, Corbet EF. Association of matrix metalloproteinase-1 promoter polymorphism with generalized aggressive periodontitis in a Chinese population. J Periodontal Res. 2005 Dec;40(6):427-31.

Carneiro E, Menezes R, Garlet GP, Garcia RB, Bramante CM, Figueira R, et al. Expression analysis of matrix metalloproteinase- 9 in epithelialized and nonepithelialized apical periodontitis lesions. Oral Surg Oral Med Oral Pathol Oral Radiol Endod. 2009 Jan;107(1):127-32.

Carneiro E, Parolin AB, Wichnieski C, Rosa EA, Silva Neto UX, Westphalen VP, et al. Expression levels of the receptor activator of NF-kB ligand and osteoprotegerin and the number of gram-negative bactéria in symtomatic asymptomatic periapical lesions. Arch Oral Biol.2017 Jan;73:166-171.

Carty M, Bowie AG. Recent insights into the role of Toll-like recep-tors in viral infection. Clin Exp Immunol. 2010 Sep;161:397-406. 
Chakraborty C, Hsu CH, Wen ZH, Lin CS, Agoramoorthy G. Zebrafish: a complete animal model for in vivo drug discovery and development. Curr Drug Metab. 2009 Feb;10(2):116-24.

Chang Y, Lai C, Yang S, Chan Y, Hsieh Y. Stimulation of matrix metalloproteinases by black-pigmented Bacteroides in human pulp and periodontal ligament cell cultures. J Endod. 2002 Feb;28(2):90-93.

Chang YC, Yang SF, Lai CC, Liu JY, Hsieh YS.Regulation of matrix metalloproteinase production by cytokines, pharmacological agents and periodontal pathogens in human periodontal ligament fibroblast cultures. J Periodontal Res. 2002 Jun;37(3):196-203.

Chiron D, Pellat-Deceunynck C, Amiot M, Bataille R, Jego G. TLR3 ligand induces NF$\mathrm{KB}$ activation and various fates of multiple myeloma cells depending on IFN-a production. J Immunol. 2009 Apr;182(7):4471-8.

Chokechanachaisakul U, Kaneko T, Okiji T, Kaneko R, Kaneko M, Kawamura J, et al. Increased gene expression of Toll like receptors and antigen-presenting cell-related molecules in the onset of experimentally induced furcation lesions of endodontic origin in rat molars. J Endod. 2010 Feb;36(2):251-5.

Cogulu D, Uzel A, Oncag O, Eronat C. PCR-based identification of selected pathogens associated with endodontic infections in deciduous and permanet teeth. Oral Surg Oral Med Oral Pathol Oral Radiol Endod. 2008 Sep;106(3):443-9.

Cohen S; Burns RC. Pathways the pulp. 6ed. St. Louis: Mosby, 1994.

Cooper PR, Holder MJ, Smith AJ. Inflammation and regeneration in the dentin-pulp complex: a double-edgedsword. J Endod. 2014 Apr;40(4 Suppl):S46-51.

Corotti MV, Zambuzzi WF, Paiva KB, Menezes R, Pinto LC, Lara VS, et al. Immunolocalization of matrix metalloproteinases-2 and -9 during apical periodontitis development. Arch Oral Biol. 2009 Aug;54(8):764-71.

Coussens LM, Fingleton B, Matrisian LM. Matrix metalloproteinase inhibitors and cancer: trials and tribulations. Science. 2002 Mar 29;295:2387-92.

Crotti T, Smith D, Hirsch R, Soukoulis S, Weedon H, Capone M, et al. Receptor activator NFkB ligand (RANKL) and osteoprotegerin (OPG) protein expression in periodontitis. J Periodontol Res. 2003 Aug:38(4):380-7. 
Curran S, Murray GI. Matrix metalloproteinases: molecular aspects of their roles in tumour invasion and metastasis. Eur J Cancer. 2000 Aug;36(13 Spec No):1621-30.

da Silva RA, Ferreira PD, De Rossi A, Nelson-Filho P, Silva LA. Toll-like receptor 2 knockout mice showed increased periapical lesion size and osteoclast number. J Endod. 2012 Jun;38(6):803-13.

Dangelo JG, Fattini CA. Anatomia humana sistêmica e segmentar. São Paulo: Atheneu, 2007, 708p.

De Nardo D. Toll-like receptors: Activation, signalling and transcriptional modulation. Cytokine. 2015 Aug;74(2):181-9.

De Oliveira KM, da Silva RA, De Rossi A, Fukada SY, Feres M, Nelson-Filho P, da Silva LA. Absence of interleukin 22 affects the oral microbiota and the progression of induced periapical lesions in murine teeth. Int Endod J. 2015 Jan;48(1):46-59.

De Rossi A, Rocha LB, Rossi MA. Interferon-gamma, interleukin-10, intercellular adhesion molecule-1, and chemokine receptor 5, but not interleukin-4, attenuate the development of periapical lesions. J Endod. 2008;34:31-38.

Deguine J, Barton GM. MyD88: a central player in innate immune signaling. F1000Prime Rep. 2014 Nov 4;6:97.

Delaissé JM, Engsig MT, Everts V, del Carmen Ovejero M, Ferreras M, Lund L, et al. Proteinases in bone resorption: obvious and less obvious roles. Clin Chim Acta. 2000 Feb;291(2):223-34.

Desai SV, Love RM, Rich AM. Seymour GJ.Toll-like receptor 2 expression in refractory periapical lesions. Int Endod J. 2011 Oct;44(10):907-16.

Devereux G, Steele S, Jagelman T, Fielding S, Muirhead R, Brady J, et al. An observational study of matrix metalloproteinase (mmp)-9 in cystic fibrosis. J Cyst Fibros 2014 Sep;13(5):557-63.

Dinarello CA. Interleukin-1 in the pathogenesis and treatment of inflammatory diseases. Blood 2011 Apr;117(14):3720-32.

Dunn MD, Park CH, Kostenuik PJ, Kapila S, Giannobile WV. Local delivery of osteoprotegerin inhibits mechanically mediated bone modeling in orthodontic tooth movement. Bone 2007;41:446 -55. 
Dziarski R, Gupta D. Role of MD-2 in TLR2- and TLR4-mediated recognition of Gramnegative and Gram-positive bacteria and activation of chemokine genes.J Endotoxin Res. 2000;6(5):401-5.

Espíndola ACS, Passos CO, Souza EDA, Santos RA. Avaliação do grau de sucesso e insucesso no tratamento endodôntico em dentes uni-radiculares. RGO. 2002;50(3):164-6.

Estrela C, Decurcio D de A, Silva JA, Batista AC, de Souza Lima NC, de Freitas Silva $B S$, et al. Immune-Inflammatory cell profile and receptor activator of nuclear factor kappa B ligand/osteoprotegerin expression in persistent apical periodont it is after root canal retreatment failure. J Endod. 2016 Mar;42(3):439-46.

Everts V, Delaissé JM, Korper W, Niehof A, Vaes G, Beertesen W. Degradation of collagen in the bone-resorbing compartment underlying the osteoclast involves both cysteine-proteinases and matrix metalloproteinases. J Cell Physiol. 1992 Feb;150 (2):221-31.

Fabricius L, Dahlén G, Öhman AE, Möller AJR. Predominant indigenous oral bacteria isolated from infected root canals after varied times of closure. Scand J Dent Res. $1982 \mathrm{Apr} ; 90(2): 134-44$.

Faggion CM Jr. Animal research as a basis for clinical trials.Eur J Oral Sci. 2015 Apr;123(2):61-4.

Fagundes DJ, Taha MO. Modelo animal de doença: critérios de escolha e espécies animais de uso corrente. Acta Cir Bras. 2004;19(1):59-65.

Forthal DN, Landucci G, Bream J, Jacobson LP, Phan TB, Montoya B. FcgammaRIIa genotype predicts progression of HIV infection. J Immunol. 2007 Dec;179(11):791623.

Gabardo MCL, Dufloth F, Sartoretto J, Hirai V, Oliveira DC, Rosa EAR. Microbiologia do insucesso do tratamento endodôntico. Revista gestão \& saúde. 2009;1(1): 11-17.

Garlet GP, Cardoso CR, Silva TA, Ferreira BR, Avila-Campos MJ, Cunha FQ, et al. Cytokine pattern determines the progression of experimental periodontal disease induced by Actinobacillus actinomycetemcomitans through the modulation of MMPs, RANKL, and their physiological inhibitors. Oral Microbiol Immunol 2006;21:12-20. 
Garlet TP, Coelho U, Silva JS, Garlet GP. Cytokine expression pattern in compression and tension sides of the periodontal ligament during orthodontic tooth movement in humans. Eur J Oral Sci 2007;115:355- 62.

Gazzinelli RT, Mendonça-Neto R, Lileu J, Howard J, Sher A. Innate resistance against Toxoplasma gondii: an evolutionary tale of mice, cats and men. All Host Microbe. 2014 Feb;15(2):132-8.

Geng DC, Xu YZ, Yang HL, Zhu GM, Wang XB, Zhu XS. Cannabinoid receptor-2 selective antagonist negatively regulates receptor activator of nuclear factor kappa $B$ ligand mediated osteoclastogenesis. Chin Med J 2011; 124: 586-590.

Ghaderi H, Kiany F, Razmkhah M, Dadras S, Chenari N, Hosseini A, et al. mRNA expression of pattern recognition receptors and their signaling mediators in healthy and diseased gingival tissues. J Indian Soc Periodontol 2014 Mar;18(2):150-4.

Gibson FC $3^{\text {rd }}$, Ukai T, Genco CA. Engagement of specific innate immune signaling pathways during Porphyromonas gingivalis induced chronic inflammation and atherosclerosis. Front Biosci. 2008 Jan 1;13:2041-59.

Godefroy E, Gallois A, Idoyaga J, Merad M, Tung N, Monu N, et al. Activation of tolllike receptor-2 by endogenous matrix metalloproteinase-2 modulates dendritic-cellmediated inflammatory responses. Cell Rep. 2014 Dec 11;9(5):1856-70.

Goetzl EJ, Banda MJ, Leppert D. Matrix metalloproteinases in immunity. J Immunol. 1996 Jan;156(1):1-4.

Gomes MT, Campos PC, de Almeida LA, Oliveira FS, Costa MM, Marim FM, et al. The role of innate immune signals in immunity to Brucella abortus. Front Cell Infect Microbiol. 2012 Oct 25;2:130.

Graves DT, Oates T, Garlet GP. Review of osteoimmunology and the host response in endodontic and periapical lesions. J Oral Microbiol. 2011 Jan;17;3.

Guise TA. Breaking down bone: new insight into site-specific mechanisms of breast cancer osteolysis mediated by metalloproteinases. Genes Dev. 2009 Sep;23 (18):2117-23.

Haapasalo M, Udnaes T, Endal U. Persistent, recurrent and acquired infection of the root canal system post-treatment. Endodontic Topics. 2003 Nov,6(1):29-56. 
Haimovich B, Calvano J, Haimovich AD, Calvano SE, Coyle SM, Lowry SF. In vivo endotoxin synchronizes and suppresses clock gene expression in human peripheral blood leukocytes. Crit Care Med. 2010 Mar;38(3):751-8.

Harokopakis-Hajishengallis E. Physiologic root resorption in primary teeth: Molecular and histological events. Journal of Oral Science. 2007 Mar;49(1):1-12.

Hayashi F, Means TK, Luster AD. Toll-like receptors stimulate human neutrophil function. Blood 2003;102:2660-9.

Hayashi F, Smith KD, Ozinsky A, Hawn TR, Yi EC, Goodlett DR, et al. The innate immune response to bacterial flagellin is mediated by Toll-like receptor 5. Nature. 2001;410(6832):1099-103.

Haynes DR, Crotti TN, Loric M, Bain GI, Atkins GJ, Findlay DM. Osteoprotegerin and receptor activator of nuclear factor kappaB ligand (RANKL) regulate osteoclast formation by cells in the human rheumatoid arthritic joint. Rheumatology 2001; 40: 623-630.

Hedayat M, Takeda K, Rezaei N. Prophylactic and therapeutic implications of toll-like receptor ligands. Med Res Rev. 2012 Mar;32(2):294-325.

Heil F, Hemmi $H$, Hochrein $H$, Ampenberger F, Kirschning C, Akira S, et al. Speciesspecific recognition of single-stranded RNA via toll-like receptor 7 and 8 . Science. 2004 Mar 5;303(5663):1526-9.

Helewski KJ, Kowalczyk-Ziomek GI, Konecki J. Neutrophils' contribution to ischaemia and reperfusion injury in liver. Wiad Lek. 2007;60(1-2):47-52.

Hemmi H, Takeuchi O, Kawai T, Kaisho T, Sato S, Sanjo H, et al. A Toll-like receptor recognizes bacterial DNA. Nature. 2000 Dec 7;408(6813):740-5.

Henderson B, Nair SP. Hard labor: bacterial infection of the skeleton. Trends Microbiol. 2003 Dec;11(12):570-7.

Hernandez M, Valenzuela MA, Lopez-Otin C, Alvarez J, Lopez JM, Vernal R, et al. Matrix metalloproteinase-13 is highly expressed in destructive periodontal disease activity. J Periodontol. 2006 Nov;77(11):1863-70.

Heywood R. The use of animals in testing.ATLA. 1987;14(4):329-33. 
Hill PA, Murphy G, Docherty AJ, Hembry RM, Millican TA, Reynolds JJ, et al. The effects of selective inhibitors of matrix metalloproteinases (MMPs) on bone resorption and the identification of MMPs and TIMP-1 in isolated osteoclasts. J Cell Sci. 1994 Nov;107:3055-64.

Hirao K, Yumoto H, Takahashi K, Mukai K, Nakanishi T, Matsuo T. Roles of TLR2, TLR4, NOD2, and NOD1 in pulp fibroblasts. J Dent Res. 2009 Aug;88(8):762-7.

Hofbauer LC, Heufeldre AE. Role of receptor activator of nuclear factor-KB ligand and osteoprotegerin in bone cell biology.J Mol Med (Berl). 2001 Jun;79(5-6):243-53.

Hoshino K, Takeuchi O, Kawai T, Sanjo H, Ogawa T, Takeda Y, et al. Cutting edge: Toll-like receptor 4 (TLR4)-deficient mice are hyporesponsive to lipopolysaccharide: evidence for TLR4 as the Lps gene product. J Immunol. 1999 Apr;162(7):3749-52.

Hou L, Sasaki H, Stashenko P. Toll-like receptor 4-deficient mice have reduced bone destruction following mixed anaerobic infection. Infection and Immunity. 2000;68:4681-7.

Hu F , Ku MC, Markovic D, a Dzaye OD, Lehnardt S, Synowitz M, et al. Glioma associated microglial MMP9 expression is up regulated by TLR2 signalling and sensitive to minocycline. Int J Cancer. 2014 Dec 1; 135(11): 2569-78.

Huang QQ, Sobkoviak R, Jockheck-Clark AR, Shi B, Mandelin 2nd AM, Tak PP, et al. Heat shock protein 96 is elevated in rheumatoid arthritis and activates macrophages primarily via TLR2 signaling. J Immunol. 2009 Apr;182(8):4965-73.

Janssens S, Beyaert R. A universal role forMyD88 in TLR/ IL-1R-mediated signaling. Trends in Biochemical Sciences 2002; 27(9): 474- 482.

Janssens S, Beyaert R. Role of Toll-like receptors in pathogen recognition. Clin Microbiol Rev. 2003 Oct;16(4):637-46.

Jiang J, Zuo J, Chen SH, Holliday LS. Calcium hydroxide reduces lipopolysaccharidestimulated osteoclast formation. Oral Surg Oral Med Oral Pathol Oral Radiol Endod. 2003 Mar;95(3):248-54.

Jin Q, Cirelli JA, Park CH, Sugai JV, Taba M Jr, Kostenuik PJ, et al. RANKL inhibition through osteoprotegerin blocks bone loss in experimental periodontitis. J Periodontol 2007; 78:1300-8. 
Kabak SL, Kabak YS, Anischenko SL. Light microscopic study of periapical lesions associated with asymptomatic apical periodontitis. Ann Anat. 2005 Apr;187(2):18594.

Kakehashi S, Stanley HR, Fitzgerald RJ.The effects of surgical exposures of dental pulps in germfree and conventional laboratory rats. Oral Surg Oral Med Oral Pathol 1965 Sep;20:340-9.

Kandaswamy D, Venkateshbabu N. Root canal irrigants. J Conserv Dent. 2010 Oct;13(4):256-64.

Kaneko T, Okiji T, Kan L, Suda H, Takagi M. An immunoelectronmicroscopic study of class II major histocompatibility complex molecule-expressing macrophages and dendritic cells in experimental rat periapical lesions. Arch Oral Biol 2001;46:713-20.

Kaneko T, Okiji T, Kan L, Takagi M, Suda H. Ultrastructural analysis of MHC class II molecule-expressing cells in experimentally induced periapical lesions in the rat. J Endod. 2001 May;27(5):337-42.

Kardong KV. Vertebrados: anatomia comparada, função e evolução. São Paulo: Rocca, 2010, 913p.

Kari G, Rodeck U, Dicker AP. Zebrafish: an emerging model system for human disease and drug discovery. Clin Pharmacol Ther. 2007 Jul;82(1):70-80.

Kassem A, Lindholm C, Lerner UH. Toll-Like Receptor 2 Stimulation of osteoblasts Mediates Staphylococcus aureus induced bone resorption and osteoclastogenesis through enhanced RANKL. PLoS One. 2016 Jun 16;11(6):e0156708.

Kawai T, Akira S. Innate immune recognition of viral infection. Nat Immunol. 2006 Feb;7(2):131-7.

Kawai $\mathrm{T}$, Akira S. The roles of $T L R s$, RLRs and NLRs in pathogen recognition. Int Immunol 2009;21(4):317-37.

Kawai T, Matsuyama T, Hosokawa Y, Makihira S, Seki M, Karimbux NY, et al. B and T lymphocytes are the primary sources of RANKL in the bone resorptive lesion of periodontal disease. Am J Pathol 2006; 169: 987-998.

Kawashima N, Stashenko P. Expression of bone-resorptive and regulatory cytokines in murine periapical inflammation. Arch Oral Biol. 1999 Jan;44(1):55-66. 
Kawashima N, Suzuki N, Yang G, Ohi C, Okuhara S, Nakano-Kawanishi $H$, et al. Kinects of RANKL, RANK and OPG expressions in experimentally inducedrat periapical lesions. Oral Surg Oral Med Oral Pathol Oral Radiol Endod.2007 May;103(5):707-11.

Kerekes K, Tronstad L. Long-term results of endodontic treatment performed with a standardized technique. J Endod 1979 Mar;5(3):83-90.

Khosla S. Minireview: the OPG/RANKL/RANK system. Endocrinology. 2001 Dec;142(12):5050-5.

Kilkenny C, Browne W, Cuthill IC, Emerson M, Altman DG. Animal research: reporting in vivo experiments: the ARRIVE guidelines. Br J Pharmacol. 2010 Aug;160(7):15779.

Kirschning CJ, Wesche $\mathrm{H}$, Merrill Ayres T, Rothe M. Human toll-like receptor 2 confers responsiveness to bacterial lipopolysaccharide. J Exp Med. 1998;188(11):2091-7.

Koblansky AA, Jankovic D, Oh $H$, Hieny S, Sungnak W, Mathur R, et al. Recognition of profilin by Toll-like receptor 12 is critical for host resistance to Toxoplasma gondii. Immunity. 2013 Jan 24;38(1):119-30.

Koh YS, Koo JE, Biswas A, Kobayashi KS. MyD88-dependent signaling contributes to host defense against ehrlichial infection. PLoS One. 2010 Jul 23;5(7):e11758.

Krug A, French AR, Barchet W, Fischer JA, Dzionek A, Pingel JT, et al. TLR9-dependent recognition of MCMV by IPC and DC generates coordinated cytokine responses that activate antiviral NK cell function. Immunity. 2004 Jul;21(1):107-19.

Krug A, Luker GD, Barchet W, Leib DA, Akira S, Colonna M. Herpes simplex virus type 1 activates murine natural interferon-producing cells through toll-like receptor 9. Blood. 2004 Feb 15;103(4):1433-7.

Leite FR, de Aquino SG, Guimarães MR, Cirelli JA, Zamboni DS, Silva JS, et al. Relevance of the myeloid differentiation factor 88 (MyD88) on RANKL, OPG, and nod expressions induced by TLR and IL-1R signaling in bone marrow stromal cells. Inflammation. 2015 Feb;38(1):1-8.

Lemaitre B, Reichhart JM, Hoffmann JA. Drosophila host defense: differential induction of antimicrobial peptide genes after infection by various classes of microorganisms. Proc Natl Acad Sci USA. 1997 Dec 23;94(26):14614-9. 
Leonardi R, Perrotta RE, Loreto C, Musumeci G, Crimi S, Dos Santos JN, et al.Toll-like receptor 4 expression in the epithelium of inflammatory periapical lesions. An immunohistochemical study.Eur J Histochem. 2015 Oct 26;59(4):2547.

Leonardo MR, Leonardo RT. Tratamento de canais radiculares: Avanços tecnológicos de uma endodontia minimamente invasiva e reparadora. São Paulo: Artes Médicas; 2012.

Leonardo MR, Rossi MA, Bonifácio KC, da Silva LA, Assed S. Scannning eléctron microscopy of the apical structure of human teeth. Ultrastruct Pathol. 2007 JulAug;31(4):321-5.

Leonardo MR, Rossi MA, Silva LA, Ito IY, Bonifácio KC. EM evaluation of bacterial biofilm and microorganisms on the apical external root surface of human teeth.J Endod. 2002 Dec;28(12):815-8.

Leone A, Angelova Volponi A, Uzzo ML, Spatola GF, Jurjus A, Vandevska-Radunovic V. Dental pulp in mature replanted human teeth: morphological alterations and metalloproteineses-2 and -9 , Annexin-5, BCL-2 and iNOS modulation. J Biol Regul Homeost Agents. 2015 Oct-Dec;29(4):961-7.

Lerner UH.Inflammation-induced bone remodeling in periodontal disease and the influence of post-menopausal osteoporosis.Journal of Dental Research. 2006 Jul;85(7):596-607.

Lerner UH.New molecules in the tumor necrosis fator ligand and receptor superfamilies with importance for physiological and pathologic bone resorption. Crit Rev Oral Biol Med. 2004 Jan 1;15(2):64-81.

Li G, Yue $Y$, Tian $Y$, Li JL, Wang M, Liang $H$, et al. Association of matrix metalloproteinase (MMP)-1, 3, 9, interleukin (IL)-2, 8 and cyclooxygenase (COX)-2 gene polymorphisms with chronic periodontitis in a Chinese population. Cytokine. 2012 Nov;60(2): 552-60.

Lima AC, Francelin C, Ferrucci DL, Stach-Machado DR, Verinaud L. Thymic alterations induced by Plasmodium berghei: expression of matrix metalloproteinases and their tissue inhibitors. Cell immunol. 2012 Sep;279(1):53-9.

Lin HY, Tang CH, Chen JH, Chuang JY, Huang SM, Tan TW, et al. Peptidoglycan induces interleukin- 6 expression through the TLR2 receptor, JNK, c-Jun, and AP-1 pathways in microglia. J Cell Physiol. 2011 Jun;226(6):1573-82. 
Lin LM, Huang GT, Rosenberg PA. Proliferation of epithelial cell rests, formation of apical cysts, and regression of apical cysts after periapical wound healing. J Endod. 2007 Aug;33(8):908-16.

Lin LM, Skribner JE, Gaengler P. Factors associated with endodontic treatment failures. J Endod. 1992 Dec;18(12):625-7.

Lin YP, Love RM, Friedlander LT, Shang HF, Pai MH. Expression of Toll-like receptors 2 and 4 and the OPG-RANKL-RANK system in inflammatory external root resorption and external cervical resorption.Int Endod J. 2013 Oct;46(10):971-81.

Liu D, Yao S, Wise GE. MyD88 expression in the rat dental follicle: implications for osteoclastogenesis and tooth eruption. Eur J Oral Sci. 2010 Aug;118(4):333-41.

Liu L,Peng B. The expression of macrophage migrationinhibitor factor is correlated with receptor activator of nuclear factor kappa B ligand in induced ratperiapicallesions. J Endod.2013 Aug;39(8):984-9.

Lund J, Sato A, Akira S, Medzhitov R, Iwasaki A. Toll-like receptor 9-mediated recognition of Herpes simplex virus-2 by plasmacytoid dendritic cells. J Exp Med. 2003 Aug 4;198(3):513-20.

Lye $E$, Mirtsos C, Suzuki N, Suzuki S, Yeh WC.The role of interleukin 1 receptorassociated kinase-4 (IRAK-4) kinase activity in IRAK-4-mediated signaling. J Biol Chem. 2004 Sep 24;279(39):40653-8.

Manning J, O'Malley D. What has the mdx mouse model of Duchenne muscular dystrophy contributed to our understanding of this disease?] Muscle Res Cell Motil. 2015 Apr;36(2):155-67.

Martinho FC, Teixeira FF, Cardoso FG, Ferreira NS, Nascimento GG, Carvalho CA, et al. Clinical Investigation of Matrix Metalloproteinases, Tissue Inhibitors of Matrix Metalloproteinases, and Matrix Metalloproteinase/Tissue Inhibitors of Matrix Metalloproteinase Complexes and Their Networks in Apical Periodontitis. J Endod. 2016 Jul;42(7):1082-8.

Marton IJ, Kiss C. Protective and destructive immune reactions in apical periodontitis. Oral Microbiol Immunol. 2000;15(3):139-150.

Matsushita K, Tajima T, Tomita K, Takada H, Nagaoka S, Torii M. Inflammatory cytokine production and specific antibody responses to lipopolysaccharide from endodontopathic black-pigmented bactéria in patients with multilesional periapical periodontitis. J Endod. 1999 Dec;25(12):795-9. 
Mc Gee JOD, Isaacson PG, Wright NA. Osford textbook of pathology.Principles of pathology. Oxford: University Press, 1992. p895.

Medzhitov R, Preston-Hurlburt P, Janeway CA Jr. A human homologue of the Drosophila Toll protein signals activation of adaptive immunity. Nature. 1997 Jul 24;388(6640):394-7.

Medzhitov R, Preston-Hurlburt P, Kopp E, Stadlen A, Chen C, Ghosh S, et al. MyD88 is an adaptor protein in the hToll/IL-1 receptor family signaling pathways. Mol Cell. 1998 Aug;2(2):253-8.

Medzhitov R. Toll-like receptors and innate immunity.Nat Rev Immunol. 2001 Nov;1(2):135-45.

Menezes R, Bramante CM, da Silva Paiva KB, Letra A, Carneiro E, Fernando Zambuzzi W,et al.Receptor activator NFkappaB-ligand and osteoprotegerin proteinexpressionin human periapical cysts and granulomas. Oral Surg Oral Med Oral Pathol Oral Radiol Endod.2006 Sep;102(3):404-9.

Menezes R, Garlet TP, Letra A, Bramante CM, Campanelli AP, Figueira Rde C, et al.Differentialpatternsofreceptor activator of nuclear factor kappa $B$ ligand/osteoprotegerin expression in human periapical granulomas: possible association with progressive or stable nature of the lesions. J Endod.2008 Aug;34(8):932-8.

Menezes-Silva R, Khaliq S, Deeley K, Letra A, Vieira AR. Genetic susceptibility to periapical disease: conditional contribution of MMP2 and MMP3 genes to the development of periapical lesions and healing response.J Endod. 2012 May;38:604-7.

Miggin SM, O'Neill LA. New insights into the regulation of TLR signaling.J Leukoc Biol. 2006 Aug;80(2):220-6.

Milanova V, Ivanovska N, Dimitrova P. TLR2elicitsIL-17-mediatedRANKL expression, IL-17, and OPG production in neutrophils from arthritic mice. Mediators Inflamm. 2014;2014: 643406.

Min $\mathrm{H}$, Hong J, Cho IH, Jang YH, Lee H, Kim D, et al. TLR2-induced astrocyte MMP9 activation compromises the blood brain barrier and exacerbates intracerebral hemorrhage in animal models. Mol Brain. 2015 Apr 10;8:23. 
Miyake K. Endotoxin recognition molecules, Toll-like receptor 4-MD-2. Semin Immubol. 2004 Feb;16(1):11-6.

Mohammadi Z. Endotoxin in endodontic infections: a review. J Calif Dent Assoc. 2011 Mar;39(3):153-61.

Mott JD, Werb Z. Regulation of matrix biology by matrix metalloproteinases. Curr Opinion Cell Biol. 2004;16:558-64.

Mukherjee S, Karmakar S, Babu SP. TLR2 and TLR4 mediated host immune responses in major infectious diseases: a review. Braz J Infect Dis. 2016 MarApr;20(2):193-204.

Murphy G. Matrix metalloproteinases and their inhibitors. Acta Orthop Scand Suppl. 1995 Oct;266:55-60.

Mutoh N, Watabe H, Chieda K, Tani-Ishii N. Expression of Toll-like receptor 2 and 4 in inflamed pulp in severe combined immunodeficiency mice.J Endod. 2009 Jul;35(7):975-80.

Nagase H, Woessner JF Jr. Matrix metalloproteinases. J Biol Chem. 1999 Jul $30 ; 274(31): 21491-4$.

Nair PN, Sjögren U, Krey G, Kahnberg KE, Sundqvist G. Intraradicular bacteria and fungi in root-filled, asymptomatic human teeth with therapy-resistant periapical lesions: a long-term light and electron microscopic follow-up study. J Endod. 1990 Dec;16(12):580-8.

Nair PN. Non-microbial etiology: Periapical cysts sustained post-treatment apical periodontitis. Endod Top. 2003;6:96-113.

Nair PN. Pathogenesis of apical periodontitis and the causes of endodontic failures. Crit Rev Oral Biol Med. 2004 Nov;15(6):348-81.

Nelson-Filho P, Leonardo MR, Silva LA, Assed S. Radiographic evaluation of the effect of endotoxin (LPS) plus calcium hydroxide on apical and periapical tissues of dogs. J Endod. 2002 Oct;28(10):694-6.

Neville, BW. Patologia oral e maxilofacial. $2^{\mathrm{a}}$ ed. Rio de Janeiro: Guanabara Koogan, 2002. 
Nilsen N, Nonstad U, Khan N, Knetter CF, Akira S, Sundan A, et al. Lipopolysaccharide and double-stranded RNA up-regulate toll-like receptor 2 independently of myeloid differentiation factor 88. J Biol Chem 2004;279:39727-35.

Nishikawa M, Yamaguchi Y, Yoshitake K, Saeki Y. Effects of TNF-alpha and prostaglandin E2 on the expression of MMPs in human periodontal ligament fibroblasts. J Periodontal Res. 2002 Jun;37(3):167-76.

Occhi IGP, Souza AA, Rodrigues V, Tomazinho LF. Avaliação de sucesso e insucesso dos tratamentos endodônticos realizados na clínica odontológica da UNIPAR. UNINGÁ Review 2011 Oct;8(2):39-46.

Ohashi K, Burkart V, Flohe S, Kolb H. Cutting edge: heat shock protein 60 is a putative endogenous ligand of the toll-like receptor-4 complex. J Immunol. 2000 Jan 15;164:558-61.

Okiji T, Kawashima N, Kosaka T, Kobayashi C, Suda H. Distribution of Ia antigenexpressing nonlymphoid cells in various stages of induced periapical lesions in rat molars. J Endod. 1994 Jan;20(1):27-31.

Oliveira-Nascimento L, Massari P, Wetzler LM. The Role of TLR2 in Infection and Immunity.Front Immunol. 2012 Apr 18;3:79.

O'Neill LA, Golenbock D, Bowie AG. The history of Toll-like receptors - redefining innate immunity.Nat Rev Immunol. 2013 Jun;13(6):453-60.

Onnis A, Navari M, Antonicelli G, Morettini F, Mannucci S, De Falco G, et al. EpsteinBarr nuclear antigen 1 induces expression of the cellular microRNA hsa-miR-127 and im-pairing B-cell differentiation in EBV-infected memory B cells. New insights into the pathogenesis of Burkitt lymphoma. Blood Cancer J. 2012 Aug 31;2:e84.

Oppenheim JJ, Tewary P, de la Rosa G, Yang D. Alarmins initiate host defense. Adv Exp Med Biol. 2007;601:185-94.

Orstavik D. Time-course and risk analyses of the development and healing of chronic apical periodontitis in man. Int Endod J. 1996 May;29(3):150-5.

Özan Ü, Ocak Z, Özan F, Oktay EA, Toptaş O, Şahman H, et al. Association of Tolllike receptors 2,3 , and 4 genes polymorphisms with periapical pathosis risk. Med Oral Patol Oral Cir Bucal. 2016 Jul;21:e408-12. 
Paula-Silva FW, da Silva LA, Kapila YL. Matrix metalloproteinase expression in teeth with apical periodontitis is differentially modulated by the modality of root cana treatment. J Endod. 2010 Feb;36:231-7.

Poltorak A, He X, Smirnova I, Liu MY, Van Huffel C, Du X, et al. Defective LPS signaling in $\mathrm{C} 3 \mathrm{H} / \mathrm{HeJ}$ and $\mathrm{C} 57 \mathrm{BL} / 10 \mathrm{ScCr}$ mice: mutations in Tlr4 gene. Science. 1998 Dec;282(5396):2085-8.

Price SJ, Greaves DR, Watkins H. Identification of novel, functional genetic variants in the human matrix metalloproteinase-2 gene: role of Sp1 in allele-specific transcriptional regulation. J Biol Chem. 2001 Mar;276(10):7549-58.

Promsudthi A, Poomsawat S, Limsricharoen W. The role of Toll-like receptor 2 and 4 in gingival tissues of chronic periodontitis subjects with type 2 diabetes. J Periodontal Res. 2014 Jun;49(3):346-54.

Rashid T, Ebringer A. Rheumatoid arthritis is linked to Proteus-the evidence. Clin Rheumatol. 2007 Jul;26(7):1036-43.

Rechenberg DK, Bostanci N, Zehnder M, Belibasakis GN. Periapical fluid RANKL and IL-8 are differentially regulated in pulpites and apical periodontitis. Cytokine. 2014 Sep;69(1):116-9.

Regan JD, Fleury AA. Irrigants in non-surgical endodontic treatment.J Ir Dent Assoc. 2006 Autmn;52(2):84-92.

Ribeiro SML, Campos P, Tirapegui J. O rato como animal de laboratório: histórico, dados biológicos e análise crítica de seu uso. Rev Farm Bioquím Univ São Paulo. 1995 Jan-Jun;31(1):21-8.

Ricucci D, Siqueira JF Jr, Bate AL, Pitt Ford TR. Histologic investigation of root canaltreated teeth with apical periodontitis: a retrospective study from twenty-four patients. J Endod. 2009 Apr;35(4):493-502.

Rider D, Furusho H, Xu S, Trachtenberg AJ, Kuo WP, Hirai K, et al. Elevated CD14 (Cluster of Differentiation 14) and Toll-Like Receptor (TLR) 4 Signaling Deteriorate Periapical Inflammation in TLR2 Deficient Mice. Anat Rec (Hoboken). 2016 Sep;299(9):1281-92.

Rietschel ET, Brade H. Bacterial endotoxins. Sci Am. 1992 Aug;267(2):54-61. 
Rocha CT, Rossi MA, Leonardo MR, Rocha LB, Nelson-Filho P, Silva LA. Biofilm on the apical region of roots in primary teeth with vital and necrotic pulps with or without radiographically evidente apical pathosis. Int Endod J. 2008 Aug;41(8):664-9.

Rossa-Junior C, Liu M, Patil C, Kirkwood KL. MKK3/6-p38 MAPK negatively regulates murine MMP-13 gene expression induced by IL-1beta and TNF-alpha in immortalized periodontal ligament fibroblasts. Matrix Biol. 2005 Oct;24(7):478-88.

Roux S, Orcel P. Bone loss. Factors that regulate osteoclast differentiation: an update. Arthrits Res. 2000;2(6):451-56.

Sakamoto M, Siqueira JF Jr, Rôças IN, Benno Y. Molecular analysis of the root canal microbiota associated with endodontic treatment failures. Oral Microbiol Immunol. 2008 Aug;23(4):275-81.

Salén JCW. Animal models: principles and problems. In: Rollin BE, Kessel ML. The experimental animal in biomedical research: care, busbandry and well-being: an overview by species. 3nd ed. Boston: CRC Press, 1995. 560p.

Santos BF. Criação e manejo de camundongos. In: Andrade A, Pinto SC, Oliveira RS. Animais de laboratório: criação e experimentação. Rio de Janeiro: Fiocruz, 2002 p.115-8.

Sato N, TakahashiN, Suda K, Nakamura M, Yamaki M, Ninomiya T, et al.MyD88 But Not TRIF Is Essential for Osteoclastogenesis Induced by Lipopolysaccharide, Diacyl Lipopeptide, and IL-1a. J Exp Med. 2004 Sep 6;200(5):601-11.

Schnare M, Holt AC, Takeda K, Akira S, Medzhitov R. Recognition of CpG DNA is mediated by signaling pathways dependent on the adaptor protein MyD88. Current Biology. 2000;10(18):1139-42.

Schwandner R, Dziarski R, Wesche $H$, Rothe M, Kirschning CJ. Peptidoglycan- and lipoteichoic acid-induced cell activation is mediated by toll-like receptor 2. J Biol Chem 1999;274(25):17406-9.

Seltzer S, Farber PA. Microbiologic factors in endodontology. Oral Surg Oral Med Oral Pathol. 1994 Nov;78(5):634-45.

Shihab PK, Al-Roub A, Al-Ghanim M, Al-Mass A, Behbehani K, Ahmad R. TLR2 and AP-1/NF-kappaB are involved in the regulation of MMP-9 elicited by heat 
killed Listeria monocytogenes in human monocytic THP-1 cells. J Inflamm (Lond). 2015 Apr 18;12:32.

Shin SJ, Lee JI, Baek SH, Lim SS. Tissue levels of matrix metalloproteinases in pulps and periapical lesions. J Endod. 2002 Apr;28(4):313-5.

Shiotani A, Shibasaki Y, Sasaki T. Localization of receptor activator of NF_B ligand, RANK $L$, in periodontal tissues during experimental movement of rat molars. J Electron Microsc. 2001;50:365-9.

Signorino G, Mohammadi N, Patane F, Buscetta M, Venza M, Venza I, et al. Role of Toll-like receptor 13 in innate immune recognition of group B Streptococci. Infct Immun 2014 Dec;82(12):5013-22.

Silva LA, Nelson-Filho P, Leonar MR, Rossi MA, Pansani CA. Effect of calcium hydroxide on bacterial endotoxin in vivo.J Endod. 2002 Feb;28(2):94-8.

Silva LA, Silva RA, Branco LG, Navarro VP, Nelson-Filho P. Quantitative radiographic evaluation of periapical boné resorption in gog's teeth contaminated with bacterial endotoxin (LPS) associated or not with calcium hydroxide. Braz Dent J. 2008;19(4):296-300.

Siqueira JF Jr, Rocas IN, Ricucci D, Hülsmann M. Causes and management of posttreatment apical periodontitis. Br Dent J. 2014 Mar;216(6):305-12.

Siqueira JF Jr, Rôças IN. Polymerase chain reaction-based analysis of microorganisms associated with failed endodontic treatment. Oral Surg Oral Med Oral Radiol Endod. 2004 Jan;97(1):85-94.

Snitkoff, GG. Testes biológicos. In: Gennaro AR. Remington: a ciência e a prática da farmácia. 20 ed. Rio de Janeiro: Guanabara Koogan, 2004. p556-68.

Song GG, Kim JH, Lee YH. Toll-like receptor (TLR) and matrix metalloproteinase (MMP) polymorphisms and periodontitis susceptibility: a meta-analysis. Mol Biol Rep. 2013 Aug;40(8):5129-41.

Sorsa T, Mantyla P, Tervahartiala T, Pussinen PJ, Gamonal J, Hernandez M. MMP activation in diagnostics of periodontitis and systemic inflammation.J Clin Periodontol. 2011 Sep;38(9):817-9. 
Sorsa T, Tjaderhane L, Konttinen YT, Lauhio A, Salo T, Lee HM, et al. Matrix metalloproteinases: contribution to pathogenesis, diagnosis and treatment of periodontal inflammation. Ann Med. 2006;38(5):306-21.

Stashenko P, Dewhirst FE, Peros WJ, Kent RL, Ago JM.Synergistic interactions between interleukin 1, tumor necrosis factor, and lymphotoxin in bone resorption. J Immunol 1987;138(5):1464-8.

Stashenko P, Teles R, D'Souza R. Periapical inflammatory responses and their modulation. Crit Rev Oral Biol Med. 1998;9(4):498-521.

Stashenko P, Wang CY, Tani-ISHII N, Yu SM. Pathogenesis of induced rat periapical lesions.Oral Surg Oral Med Oral Pathol. 1994 Oct;78(4):494-502.

Stashenko $\mathrm{P}, \mathrm{Yu} \mathrm{SM}$, Wang $\mathrm{CY}$. Kinects of immune cell and bone resorptive responses to endodontic infections.J Endod. 1992 Sep;18(9):422-6.

Stashenko P, Yu SM. T Helper and T Supressor cell reversal during the development of induced rat periapical lesion. J Dent Res. 1989 May;68(5):830-4.

Stashenko P. Role of immune cytokines in pathogenesis of periapical lesions.Endod Dent Traumatol. 1990 Jun;6(3):89-96.

Suzuki T, Kumamoto $H$, Ooya $K$, Motegi K. Expression of inducible nitric oxide synthase and heat shock proteins in periapical inflammatory lesions. J Oral Pathol Med. 2002 Sep;31(8):488-93.

Suzuki T, Suda N, Ohyama K. Osteoclastogenesis during mouse tooth germ development is mediated by receptor activator of NFkB ligand (RANKL). J Bone Miner Metab. 2004;22:185-91.

Takeda K, Akira S. Microbial recognition by Toll-like receptors. J Dermatol Sci. 2004 Apr;34(2):73-82.

Takeda K, Akira S. Toll-like receptors in innate immunity. Int Immunol. 2005 Jan;17(1):1-14.

Takeuchi O, Hoshino K, Akira S. Cutting edge: TLR2-deficient and MyD88-deficient mice are highly susceptible to Staphylococcus aureus infection. J Immunol. 2000 Nov;165(10):5392-6. 
Tang $Y$, Sun $F$, Li X, Zhou $Y$, Yin S, Zhou X. Porphyromonas endodontalis lipopolysaccharides induce RANKL by mouse osteoblast in a way different from that of Escherichia coli lipopolysaccharide. J Endod. 2011 Dec;37(12):1653-8.

Tay JY, Bay BH, Yeo JF, Harris M, Meghji S, Dheen ST. Identification of RANKL in osteolytic lesions of the facial skeleton. J Dent Res. 2004 Apr;83(4):349-53.

Teitelbaum SL. Bone resorption by osteoclasts. Science 2000; 289: 1504-1508.

Teng YT, Nguyen H, Gao X, Kong YY, Gorczynski RM, Singh B, et al. Function human T-cell immunity and osteoprotegerin ligand control alveolar bone destruction in periodontal infection. J Clin Invest. 2000 Sep;106(6):R59-67.

Theill LE, Boyle WJ, Penninger JM. RANK-L and RANK: T cells, bone loss, and mammalian evolution. Annu Rev Immunol. 2002;20:795-823.

Thomaz JM, Carvalho AF, Miglino MA, Maçanares CAF, Ambrósio CE, Oliveira MF. Caracterização morfológica dos dentes de mocó Kerodon rupestris: Mammalia: Rodentia. Braz J Vet Anim Sci. 2006;43(5):702-707.

Tronstad L. Recent development in endodontic research. Scand J Dent Res. 1992 Feb;100(1):52-9.

Tsuji M, Yamasaki M, Amano K, Matsui H, Morimoto T, Nakamura H. Histochemical localization of neutral proteases released during development of rat periradicular lesion. Arch Oral Biol. 2009 Dec;54(12):1128-35.

Uematsu S, Jang MH, Chevrier N, Guo Z, Kumagai Y, Yamamoto M, et al. Detection of pathogenic intestinal bacteria by Toll-like receptor 5 on intestinal CD11C+ lamina propria cells. Nature Immunol. 2006 Aug;7(8):868-74.

Ukai T, Yumoto H, Gibson FC 3rd, Genco CA. Macrophage-elicited osteoclastogenesis in response to bacterial stimulation requires Toll-like receptor 2 dependent tumor necrosis factor-alpha production. Infect Immun. 2008 Feb;76(2):812-9.

Underhill DM, Ozinsky A. Toll-like receptors: key mediators of microbe detection. Curr Opin Immunol. 2002 Feb;14(1):103-10.

Vabulas RM, Ahmad-Nejad P, Ghose S, Kirschning CJ, Issels RD, Wagner H. HSP70 as endogenous stimulus of the Toll/interleukin-1 receptor signal pathway. J Biol Chem. 2002 Apr 26;277:15107-12. 
Van Bodegom D, May L, Meij HJ, Wesrendorp RG. Regulation of human life histories: teh role of the inflammatory host response. Ann N Y Acad Sci. 2007 Apr;1100:84-97.

van der Vlugt LE, Haeberlein S, de Graaf W, Martha TE, Smits HH. Toll-like receptor ligation for the induction of regulatory B cells.Methods Mol Biol. 2014;1190:127-41.

van der Zee E, Everts V, Beertsen W. Cytokine-induced endogenous procollagenase stored in the extracellular matrix of soft connective tissue results in a burst of collagen breakdown following its activation. J Peridontol Res. 1996 Oct;31(7):483488.

Verstak B, Nagpal K, Bottomley SP, Golenbock DT, Hertzog PJ, Mansell A. MyD88 adapter-like (Mal)/TIRAP interaction with TRAF6 is critical for TLR2 and TLR4mediated NF-kB proinflammatory responses. J Biol Chem. 2009 Sep;284(36):24192203.

Wahlgren J, Salo T, Teronen O, Luoto H, Sorsa T, Tjäderhane L. Matrix metalloproteinase-8 (MMP-8) in pulpal and periapical inflammation and periapical root-canal exudates. Int Endod J. 2002 Nov;35(11):897-904.

Wan C, Yuan G, Yang J, Sun Q, Zhang L, Zhang J, et al. MMP9 deficiency increased the size of experimentally induced apical periodontitis. J Endod. 2014 May;40(5):65864.

Wang F, Zhang P, Yang L, Yu X, Ye X, Yang J, et al. Activation of toll-like receptor 2 promotes invasion by upregulating MMPs in glioma stem cells. Am J Transl Res. 2015 Mar;7(3):607-15.

Wang F, Zhang P, Yang L, Yu X, Ye X, Yang J, et al. Activation of toll-like receptor 2 promotes invasion by up-regulating MMPs in glioma stem cells. Am J Transl Res. 2015 Mar 15;7(3):607-15. eCollection 2015.

Wang JQ, Jeelall YS, Ferguson LL, Horikawa K. Toll-like receptors and cancer: MyD88 mutation and inflammation. Front Immunol. 2014 Jul 31;5:367.

Wang YY, Myhre AE, Pettersen SJ, Dahle MK, Foster SJ, Thiemermann C, et al. Peptidoglycan of staphylococcus aureus induces enhanced levels of matrix metalloproteinase-9 in human blood originating from neutrophils. Shock. 2005 Sep;24(3):214-8. 
Wittrant Y, Theoleyre S, Chipoy C, Padrines M, Blanchard F, Heymann D, et al. RANKL/RANK/OPG: new therapeutic targets in bone tumours and associated osteolysis. Biochim Biophys Acta. 2004 Sep 20;1704(2):49-57.

Yamagishi VT, Torneck CD, Friedman S, Huang GT, Glogauer M. Blockade of TLR2 inhibits Porphyromonas gingivalis suppression of mineralized matrix formation by human dental pulp stem cells. J Endod. 2011 Jun;37(6):812-8.

Yang J, Ryu $\mathrm{YH}$, Yun $\mathrm{CH}$, Han SH.Impaired osteoclastogenesis by staphylococcal lipoteichoic acid through Toll-like receptor 2 with partial involvement of MyD88.J Leukoc Biol. 2009 Oct;86(4):823-31.

Yang S, Takahashi N, Yamashita T, Sato N, Takahashi M, Mogi M, et al. Muramyl dipeptide enhances osteoclast formation induced by lipopolysaccharide, IL-1 alpha, and TNF-alpha through nucleotide-binding oligomerization domain 2-mediated signaling in osteoblasts. J Immunol. 2005 Aug;175(3):1956-64.

Yarovinsky F, Zhang D, Andersen JF, Bannenberg GL, Serhan CN, Hayden MS, et al. TLR11 activation of dendritic cells by a protozoan profilin-like protein. Science. 2005 Jun 10;308(5728):1626-9.

Yasuda H, Shima N, Nakagawa N, Yamaguchi K, Kinosaki M, Mochizuki S, et al. Osteoclast differentiation factor is a ligand for osteoprotegerin/osteoclastogenesisinhibitory factor and is identical to TRANCE/RANKL. Proc Natl Acad Sci USA. 1998 Mar 31;95(7):3597-602.

Yumoto H, Hirota K, Hirao K, Miyazaki T, Yamamoto N, Miyamoto K, et al. Antiinflammatory and protective effects of 2-methacryloyloxyethyl phosphorylcholine polymer on oral epithelial cells. J Biomed Mater Res A. 2015 Feb;103(2):555-63.

Zhang P, Liu J, Xu Q, Harber G, Feng X, Michalek SM, et al. TLR2-dependent modulation of osteoclastogenesis by Porphyromonas gingivalis through differential induction of NFATc1 and NF-kappaB. J Biol Chem. 2011 Jul 8;286(27):24159-69. 

Anexos 



\section{ANEXo A}

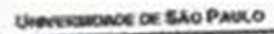

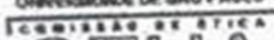

UNIVERSIDADE DE SÃO PAULO

Campus de Ribeirăo Preto

Comissäo de Etica no Uso de Animais

\section{E R T I F I C A D O}

Certificamos que o trabalho (Protocolo $n^{\circ}$ 11.1.91.53.0), intitulado "Estudo da Gênese e Progressāo de Lesōes Periapicais Induzidas Experimentalmente em Dentes de Camundongos Transgênicos", de autoria de Paula Dariana Fernandes Ferreira, e de Raquel Assed Bezerra da Silva por estar de acordo com os Principios Éticos na Experimentação Animal adotado pela Comissăo de Ética no Uso de Animais (CEUA) do Campus de Ribeirăo Preto - USP foi aprovado em reunião da CEUA de 01/06/2011.

This is to certify that the work (Protocol number 11.1.91.53.0), entitled: "Estudo da Gênese e Progressấo de Lesŏes Periapicais Induzidas Experimentalmente em Dentes de Camundongos Transgènicos", by Paula Dariana Fernandes Ferreira and Raquel Assed Bezerra da Silva, is in accordance with the Ethic Principles in Animal Experimentation adopted by Ethic Commission for the Use of Animals (CEUA) of the Campus of Ribeirăo Preto - USP, and was approved in the meeting, June 01, 2011.

Ribeirão Preto, 6 de junho de 2011.

Emitai Lectipanusi

Presidente da CEUA

Profa. Dra. Christie Ramos Andrade Leite Panissi

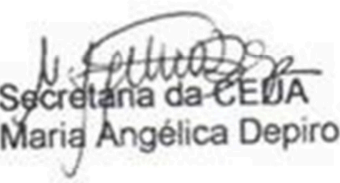

Av. Bandeirantes, 3900 - CEP $14040-900$ - Robeirdo Preto - S3o Paulo Fone: (16) 36024469 - Fax (16) 36337964 


\section{ANEXO B}

\section{UNIVERSIDADE DE SÃO PAULO \\ FACULDADE DE ODONTOLOGIA DE RIBEIRÃO PRETO \\ Comissão de Ética no Uso de Animais}

Of. CEUA 006/2015

Ribeirão Preto, 25 de fevereiro de 2015.

Ref. processo $n^{\circ}$ 2014.1.911.58.0

Senhor(a) Pesquisador(a),

Informamos que a Comissão de Ética no Uso de Animais da FORP, em sua $24^{a}$ Sessão Ordinária, realizada em 25 de fevereiro de 2015, referendou a aprovação do projeto "Aspectos moleculares e fenotípicos de lesões periapicais em modelo animal knockout para TLR-2 e MyD88", emitindo o certificado anexo.

Informamos, também, que deverá ser entregue na Secretaria da CEUA, até o dia 28/10/2016, o Relatório Final contendo os resultados e/ou resumo do trabalho publicado.

Atenciosamente,

Profa. Dra.Andiara De Rossi Daldegan

Coordenadora da Comissão de Ética no Uso de Animais

Ilmo(a). Sr(a).

Profa. Dra. Raquel Assed Bezerra Segato

Departamento de Clínica Infantil

desta Faculdade

/aafn 